\title{
Ion adsorption and diffusion in smectite: molecular, pore, and continuum scale views
}

Ruth M. Tinnacher ${ }^{\mathrm{a},{ }^{*}}$, Michael Holmboe ${ }^{\mathrm{a}, \mathrm{b}}$, Christophe Tournassat ${ }^{\mathrm{a}, \mathrm{c}}$, Ian C. Bourg ${ }^{\mathrm{a}, \mathrm{d}}$,

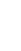

${ }^{\mathrm{d}}$ Department of Civil and Environmental Engineering (CEE) and Princeton Environmental Institute (PEI),
Princeton University, Princeton, NJ 08544, United States

*Corresponding author: RMTinnacher@lbl.gov

Phone: (510) 4958231

${ }^{\mathrm{b}}$ Department of Chemistry, Umeå University, Uppsala, Sweden

${ }^{\mathrm{c}}$ BRGM, French Geological Survey, Orléans, France

22 Keywords: diffusion, clay, models, reactive transport, molecular dynamics, pore structure, diffuse 23 layer, free water. 


\section{Abstract}

2 Clay-rich media have been proposed as engineered barrier materials or host rocks for high level 3 radioactive waste repositories in several countries. Hence, a detailed understanding of adsorption 4 and diffusion in these materials is needed, not only for radioactive contaminants, but also for 5 predominant earth metals, which can affect radionuclide speciation and diffusion. The prediction 6 of adsorption and diffusion in clay-rich media, however, is complicated by the similarity between 7 the width of clay nanopores and the thickness of the electrical double layer (EDL) at charged clay 8 mineral-water interfaces. Because of this similarity, the distinction between 'bulk liquid' water 9 and 'surface' water (i.e., EDL water) in clayey media can be ambiguous. Hence, the goal of this

10 study was to examine the ability of existing pore scale conceptual models (single porosity 11 models) to link molecular and macroscopic scale data on adsorption and diffusion in compacted 12 smectite. Macroscopic scale measurements of the adsorption and diffusion of calcium, bromide, 13 and tritiated water in Na-montmorillonite were modeled using a multi-component reactive 14 transport approach while testing a variety of conceptual models of pore scale properties 15 (adsorption and diffusion in individual pores). Molecular dynamics (MD) simulations were 16 carried out under conditions similar to those of our macroscopic scale diffusion experiments to 17 help constrain the pore scale models. Our results indicate that single porosity models cannot be 18 simultaneously consistent with our MD simulation results and our macroscopic scale diffusion data. A dual porosity model, which allows for the existence of a significant fraction of bulk liquid water-even at conditions where the average pore width is only a few nanometers - may be required to describe both pore scale and macroscopic scale data.

\section{Introduction}

24 Nuclear fission produces $14 \%$ of the world's electricity supply and could contribute $\sim 15 \%$ of $\mathrm{CO}_{2}$ abatement efforts required to stabilize global $\mathrm{CO}_{2}$ emissions over the next 50 years (Pacala and Socolow, 2004; Englert et al., 2012). The viability of nuclear energy as a $\mathrm{CO}_{2}$ abatement technology, however, relies in part on the demonstration that geologic storage facilities can isolate high level radioactive waste (HLRW) on time scales commensurate with the decay of long-lived radioactive fission products, on the order of $10^{6}$ years. Accurate predictions of repository performance on such long time scales require the development of geophysical models grounded in fundamental knowledge of material properties and constitutive relationships relevant to radionuclide migration in geologic media (Altmann et al., 2012).

33 Most countries with HLRW storage programs are currently investigating clayey media, such as bentonite and shale, for use as engineered barriers and/or host rocks of geologic repositories (Andra, 2005; Delay et al., 2007; Altmann, 2008; Guyonnet et al., 2009; Bock et al., 2010; SKB, 2011; Altmann et al., 2012). At the conditions that would exist in proposed HLRW repositories, 
1 and water and solute mass fluxes that are dominated by molecular diffusion on time-scales of 2 millions of years (Neuzil, 1986, 1994, 2013; Horseman and Volckaert, 1996; Oscarson et al., 3 1996; Bock et al., 2010; Mazurek et al., 2011). The diffusion coefficients of water and solutes in 4 clayey media have been extensively studied in conditions relevant to HLRW repositories, 5 particularly in the case of water tracers (HTO), anions $\left(\mathrm{I}^{-}, \mathrm{Br}^{-}, \mathrm{Cl}^{-}, \mathrm{TcO}_{4}^{-}, \mathrm{SeO}_{3}{ }^{2-}\right.$ ), and alkali and 6 alkaline earth metals $\left(\mathrm{Na}^{+}, \mathrm{Cs}^{+}, \mathrm{Ca}^{2+}, \mathrm{Sr}^{2+}\right)$ (Appelo et al., 2010; Savoye et al., 2010, 2011; 7 Gimmi and Kosakowski, 2011; Holmboe et al., 2011; Loomer et al., 2013; Tachi and Yotsuji, 2014; Bourg and Tournassat, 2015). It is important to note that an understanding of diffusion rates is needed for both relevant radionuclides and predominant earth metals, because the latter elements can affect actinide solution speciation and compete with radionuclides for mineral surface sites. For instance, within engineered clay barriers containing minor amounts of calcite, $\mathrm{Ca}_{2} \mathrm{UO}_{2}\left(\mathrm{CO}_{3}\right)_{3}{ }^{0}$ is expected to dominate uranium(VI) solution speciation, and hence, control U(VI) sorption and diffusion behavior (Kerisit and Liu, 2010; Bradbury and Baeyens, 2011; Joseph et al., 2011).

Sodium-montmorillonite is the main constituent of bentonite, the engineered barrier material considered for use in HLRW repositories in many countries (Nadeau, 1985; Zachara and Smith, 1994; Sposito et al., 1999; Tournassat et al., 2003; Yokoyama et al., 2005). Montmorillonite is a smectite, a 2:1-layer-type dioctahedral phyllosilicate with a large specific surface area ( 800 $\left.\mathrm{m}^{2} \cdot \mathrm{g}^{-1}\right)$ and cation exchange capacity $\left(\sim 1 \mathrm{mmol}_{\mathrm{c}} \cdot \mathrm{g}^{-1}\right)$, each clay mineral layer having a thickness of $\sim 1 \mathrm{~nm}$ and carrying negatively-charged isomorphic substitutions in its phyllosilicate framework. The aggregation of Na-montmorillonite layers into particles (i.e., stacks of clay mineral layers) results in a complex pore-size distribution including narrow ( 1 nm wide) interlayer pores within particles (where diffusion is strongly impacted by clay mineral surfaces) and larger pores between particles (where water may be bulk-liquid-like).

Diffusion of dilute conservative solutes in porous media can be described using an effective diffusion coefficient $D_{\mathrm{e}}$ defined by the following Fickian expression:

$$
J=-D_{e} \frac{\partial C_{b}}{\partial x}
$$

where $J$ is the solute mass flux density in the $x$ direction and $C_{\mathrm{b}}$ is the concentration of the species of interest in bulk pore water. (Units for all variables are provided in the Notation section.) If adsorption is linear and instantaneous, eq 1 can be combined with a local mass balance relation to obtain the expression:

$$
\alpha \frac{\partial C_{b}}{\partial t}=\frac{\partial}{\partial x}\left[D_{e} \frac{\partial C_{b}}{\partial x}\right]
$$

where the rock capacity factor $\alpha$ depends on porosity $\theta$, the dry bulk density of the porous medium $\rho_{\mathrm{b}}$, and the slope of the linear sorption isotherm $K_{\mathrm{D}}$ according to the relation:

$$
\alpha=\theta+\rho_{b} K_{D}
$$


1 In macroporous media, $D_{\mathrm{e}}$ depends only on $\theta$, a geometric factor $G(\geq 1)$ that describes the 2 influence of pore-network geometry [i.e., the orientation, shape, and connectivity of pores (Bear, 3 1972; Dykhuizen and Casey, 1989; Shackelford and Moore, 2013)], and the self-diffusion 4 coefficient of the species of interest in bulk liquid water $D_{0}$ :

$$
D_{e}=\frac{\theta}{G} D_{0}
$$

5 In clayey media, however, eq 4 overestimates the diffusion of anions and underestimates the 6

(b) the lower effective or "anion-accessible" porosity $\left(\theta_{\mathrm{e}} \leq \theta\right.$, eq 6) due to anion exclusion (negative adsorption) in the EDL (Van Schaik and Kemper, 1966; Mazurek et al., 2011; Shackelford and Moore, 2013),

$$
D_{\text {e,anion }}=\frac{\theta_{\mathrm{e}}}{G} D_{0}
$$
and (c) the significant mobility of adsorbed cations in the EDL (Jenny and Overstreet, 1939; Van 33 surface diffusion coefficient $D_{\mathrm{s}}$ (eq 7). 


$$
D_{\text {e,cation }}=\frac{\theta}{G} D_{0}+\rho_{\mathrm{b}} K_{\mathrm{D}} D_{\mathrm{s}}
$$

1 Equations 5-7 provide convenient phenomenological descriptions of $D_{\mathrm{e}}$, but their predictive 2 capabilities, inherently, are contingent upon the existence of accurate models for the newly 3 introduced parameters $\left(q_{\mathrm{nano}}, \theta_{\mathrm{e}}, K_{\mathrm{D}}\right.$, and $\left.D_{\mathrm{s}}\right)$.

4 A second approach consists in developing conceptual models of adsorption and diffusion in 5 individual, slit-shaped clay nanopores, and then, using these pore scale models to predict 6 macroscopic-scale $D_{\mathrm{e}}$ values in clayey media (Leroy et al., 2006; Birgersson and Karnland, 2009;

7 Jougnot et al., 2009; Appelo et al., 2010; Tachi and Yotsuji, 2014; Tachi et al., 2014). The 8 availability of a large variety of single porosity models (Fig. 1) suggests that existing 9 macroscopic scale data do not strongly constrain all features in these models. In particular, two 10 significant challenges hinder efforts to constrain the pore-scale models summarized in Fig. 1. 11 Firstly, the structure of the EDL in clayey media has never been directly observed: existing 12 models are based on theoretical calculations (Sposito, 1992) or atomistic simulations (Marry et 13 al., 2002, 2008; Tournassat et al., 2009; Bourg and Sposito, 2011). Secondly, the microstructure 14 of water-saturated clayey media is not precisely known in the range of conditions relevant to 15 HLRW repositories (high solid-water ratios, broad range of salinities). As a consequence, these 16 models use the simplifying assumption (explicitly or implicitly) that clayey media are dominated 17 by slit-shaped pores with a pore width $h_{\text {pore }}$, equal to the average pore width in the medium. This 18 simplification obviates the need for information on the microstructure of the medium, because the 19 average pore width can be calculated from the dry bulk density $\rho_{\mathrm{b}}$ and specific surface area $a_{\mathrm{s}}$ of 20 the material. Experimental studies using X-ray diffraction (Ferrage et al., 2005; Holmboe et al., 21 2012), small angle neutron scattering (Swift et al., 2014), and nuclear magnetic resonance 22 (Montavon et al., 2009), however, show that pore-size distributions in clayey media are often 23 bimodal or more complex, raising questions about the appositeness of the "single pore width" 24 assumption. 


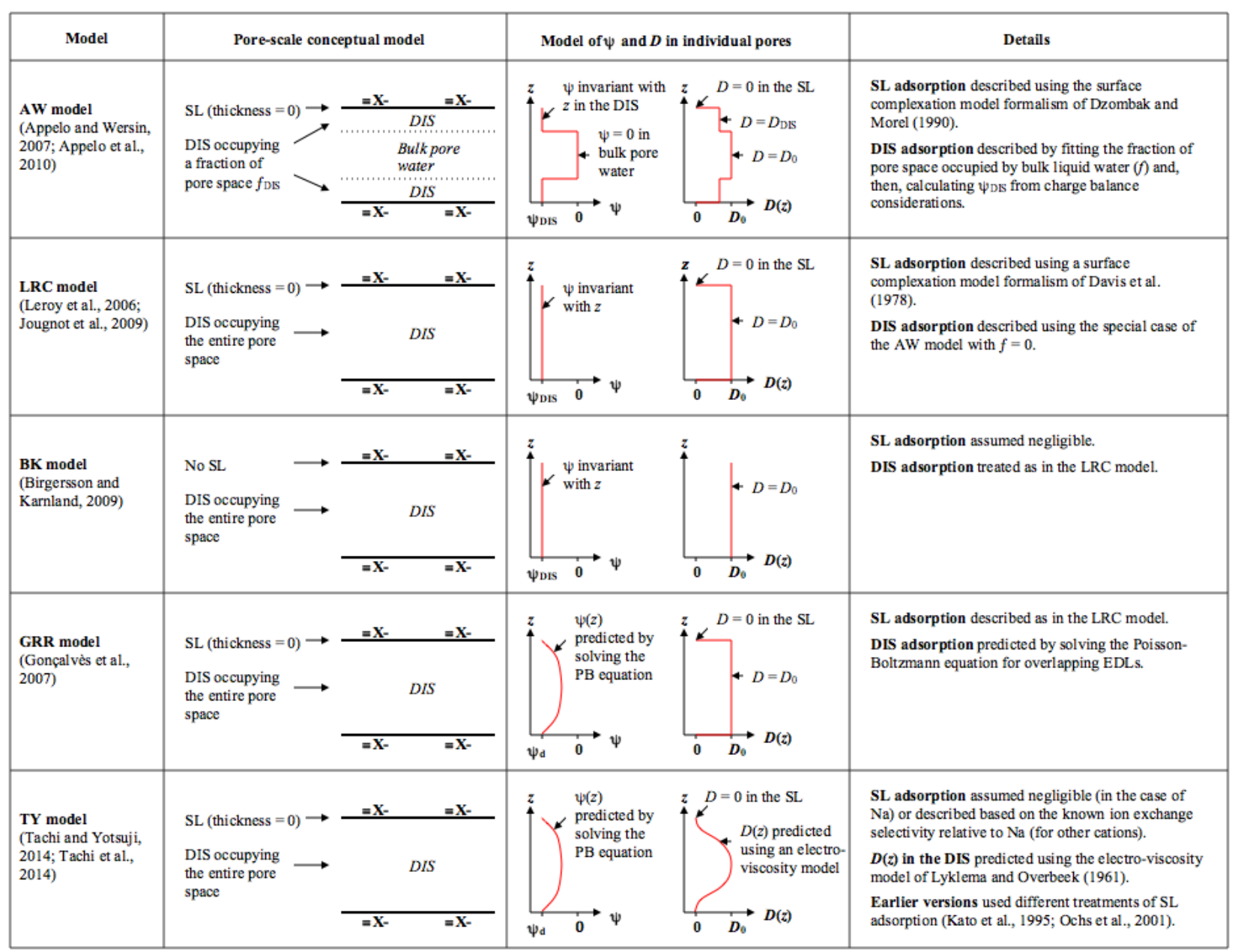

2 Fig. 1. Overview of pore-scale conceptual models describing diffusion and adsorption processes

3 in clay interlayer spaces as single porosity (AW, LRC, BK, GRR, TY) models. Model names are 4 based on authors of related publications. The electrical double layer (EDL) is almost invariably 5 modeled as the sum of a Stern layer (SL) and a diffuse ion swarm (DIS), the latter being 6 characterized by the electrostatic potential profile across the pore, $\psi(z)$.

7 A third approach consists in developing models of water and ion diffusion that account for the 8 pore-size distribution in clayey media. Models of this type have been used to describe water and 9 cation diffusion (Bourg et al., 2006; Bourg and Sposito, 2010; Churakov and Gimmi, 2011; 10 Bourg and Tournassat, 2015), anion exclusion (Tournassat and Appelo, 2011), pore water 11 geochemistry (Wersin et al., 2004), and swelling mechanics (Wang et al., 2013). The challenge is 12 that the microstructure of clay barriers is arduous to characterize with sufficient resolution to 13 constrain existing models: X-ray diffraction techniques can detect the smallest pores present in 14 smectite clay barriers $(0.3$ to $0.9 \mathrm{~nm})$ and some larger scale features, such as osmotic hydrates 15 and interstratified stacking arrangements, but they are limited with regard to larger-scale stacking 16 arrangements and sensitive to sample preparation techniques (Holmboe et al., 2010, 2012). 17 Electron microscopy techniques are not yet able to probe the microstructure of the smallest pores 
1 in compacted clayey media due to beam damage and microstructural changes during sample 2 preparation.

3 The present situation clearly indicates two research questions: (1) Do single porosity models, 4 summarized in Fig. 1, correctly predict ion density and diffusion profiles across clay nanopores? and (2) Is the use of an average pore width sufficient to describe diffusion in clayey media, or are 6 models accounting for a distribution of pore sizes needed?

7 In order to answer these questions, we performed a combined experimental and modeling study 8 to examine the consistency of macroscopic adsorption and diffusion measurements, pore scale 9 models, and molecular dynamics (MD) simulations in the case of cations, anions, and uncharged 10 species in a single effort and over multiple scales. First, we present new macroscopic scale 11 measurements of the adsorption and diffusion of trace levels of $\mathrm{Ca}^{2+}, \mathrm{Br}^{-}$, and tritiated water 12 (HTO) in water-saturated Na-exchanged smectite (montmorillonite). The results are then 13 modeled using a multi-component reactive transport approach based on the models described in 14 Fig. 1. Model assumptions and parameters are then tested against new MD simulation results on 15 water and ion adsorption and diffusion in individual clay interlayer nanopores carried out under 16 similar conditions to our laboratory diffusion experiment. These combined results allow us to 17 critically evaluate the underlying assumptions of the models compiled in Fig. 1, and the ability of 18 these models to link the pore scale and macroscopic scale properties of compacted smectite. Our

\section{2. Experimental and modeling methods}

\section{2.1. Experimental}

\subsubsection{Clay pretreatment and characterization}

A commercially available, well-characterized standardized Source Clay (Na-montmorillonite, SWy-2, The Clay Minerals Society) was selected in order to allow for a subsequent comparison with other data from the literature. The material is known to contain significant amounts of impurities including quartz (8\%), feldspars (16\%) and calcite (Chipera and Bish, 2001; Costanzo and Guggenheim, 2001; Mermut and Cano, 2001). Prior to its use, the clay was pretreated to remove major mineral impurities while preserving the original clay characteristics as much as possible, following an adaptation of published methods (Jackson, 1975). The complete procedure is described in detail in the Electronic Annex (EA). Briefly, pretreatment steps included: the removal of calcite impurities using a $1 \mathrm{M}$ sodium acetate/glacial acetic acid solution $(0.564 \mathrm{M})$ at $\mathrm{pH} 5$; clay equilibration with a $1 \mathrm{M}$ sodium chloride solution; removal of excess salts with Nanopure water; separation of quartz and feldspar impurities from the $<2 \mu \mathrm{m}$ clay fraction by centrifugation; and oven-drying of the purified clay at $45^{\circ} \mathrm{C}$. This purification 
1 procedure allowed us to keep calcium background concentrations at or below $88.1 \mu \mathrm{g} \cdot \mathrm{dm}^{-3}$ in the 2 reservoir solutions during the through-diffusion experiment, with a contribution of $33.2 \mu \mathrm{g} \cdot \mathrm{dm}^{-3}$

3 from the background electrolyte itself. All chemicals used in this study were reagent grade or

4 better. Acids, bases, and salt solutions used in experiments were of TraceSelect (Sigma Aldrich) or comparable grade in order to minimize calcium background concentrations.

\subsubsection{Calcium bromide through-diffusion experiment}

The calcium bromide through-diffusion experiment largely followed procedures previously described in the literature (Molera and Eriksen, 2002; Van Loon et al., 2003a; b). The experimental setup consists of a diffusion cell, high and low concentration reservoirs, and a peristaltic pump (Fig. EA-1, Electronic Annex). All experimental solutions were repeatedly adjusted to $\mathrm{pH} 7$ using small volumes of acid/base solutions (TraceSelect grade $\mathrm{NaOH}$ and $\mathrm{HCl}$ ), while equilibrating with atmospheric $\mathrm{CO}_{2}$ over 3-6 days, prior to their contact with the mineral phase.

At the beginning of the experiment, dry, pretreated Na-montmorillonite was packed into the diffusion cell (PEEK; $\mathrm{D}=1.0 \mathrm{~cm}, \mathrm{~L}=0.5 \mathrm{~cm}$; Alltech $2 \mu \mathrm{m}$ stainless-steel frits, $\mathrm{P} / \mathrm{N}$ 721825) by hand to obtain a dry bulk density of $0.8 \pm 0.03 \mathrm{~kg} \cdot \mathrm{dm}^{-3}$. This dry density value was selected in order to test a system where both clay macro- and micro-pore structures may be relevant and to ensure solute breakthrough within reasonable, experimental time-frames. For comparison, dry densities of compacted bentonite in proposed waste repositories are expected at around 1.6 $\mathrm{kg} \cdot \mathrm{dm}^{-3}$. The clay was carefully compacted with a custom-made PEEK rod and, then, saturated with the background electrolyte $(0.1 \mathrm{M} \mathrm{NaCl}, \mathrm{pH}$ 7) by circulating electrolyte solutions at 0.7 $\mathrm{mL} \cdot \mathrm{min}^{-1}$ for about $4 \frac{1}{2} 2$ weeks.

After clay saturation, the solutions in the high and low concentration reservoirs were replaced by $200 \mathrm{~mL}$ of background electrolyte containing $1 \mathrm{mM} \mathrm{CaBr}_{2}$ and a $20 \mathrm{~mL}$ aliquot of fresh, $\mathrm{CaBr}_{2}-$ free electrolyte, respectively. Over the following weeks, the circulation of solutions was continued at the same flow rate. Electrolyte solutions in the low concentration reservoir were regularly replaced in order to maintain a nearly constant concentration gradient between the high and low concentration reservoirs, with $<0.02 \mathrm{mM} \mathrm{CaBr}_{2}$ in the low concentration reservoir at all times. The collected low concentration reservoir vials were weighed to correct for volume losses due to evaporation. Solutions were sampled for $\mathrm{Ca}$ and $\mathrm{Br}$ analysis by ion chromatography (IC) and flow injection analysis (FIA), respectively (Lachat QuikChem 8500 Series 2 Automated Ion Analyzer, IC Cations: method: \#10-520-00-1-D, FIA-Bromide method: \#30-135-21-1-A), and their solution $\mathrm{pH}$ values were recorded. In addition, small volumes $(1.5 \mathrm{~mL})$ of the high concentration reservoir solution were regularly sampled for the monitoring of $\mathrm{Ca}$ and $\mathrm{Br}$ concentrations and concentration gradients. This procedure was continued until a series of data points had been collected under steady-state $\mathrm{Ca}$ and $\mathrm{Br}$ diffusion. The solution in the high concentration reservoir was then replaced with a $\mathrm{CaBr}_{2}$-free background electrolyte containing approximately $1000 \mathrm{~Bq} \cdot \mathrm{mL}^{-1}\left(27 \mathrm{nCi} \cdot \mathrm{mL}^{-1}\right)$ of tritiated water $(\mathrm{HTO})$. Again, low concentration reservoir solutions were continuously replaced, and tritium activities were analyzed (PerkinElmer 
1 Liquid Scintillation Analyzer Tri-Carb 2900TR; Ultima Gold XR liquid scintillation cocktail)

2 until a sufficient number of data points had been collected under steady-state HTO diffusion.

\subsubsection{Determination of anion-accessible porosity}

Preliminary modeling results showed a difference between the diffusion-accessible porosity for tritiated water (HTO) and the anion (bromide) in packed Na-montmorillonite. Hence, a "static" experiment was conducted to determine the anion-accessible porosity using the same background electrolyte solution and a similar bromide concentration as in the through-diffusion experiment. In the static experiment, the diffusion cell containing the dry packed clay was directly connected to two $200 \mathrm{~mL}$, high concentration reservoirs $(0.1 \mathrm{M} \mathrm{NaCl}, 0.00085 \mathrm{M} \mathrm{NaBr}, \mathrm{pH}$ 7) in order to facilitate a faster equilibration of the clay with bromide ions. After equilibration for 33 days, the wet clay was extruded and dried at $150{ }^{\circ} \mathrm{C}$ to determine its water content by weight difference and to compute the dry bulk density of the porous medium. Bromide was extracted from the dried and ground mineral phase by leaching (Muurinen et al., 2004, 2007; Van Loon et al., 2007). Briefly, aliquots of approximately $30 \mathrm{mg}$ Na-montmorillonite were transferred into $15-\mathrm{mL}$ centrifuge tubes (four replicates) and $10-\mathrm{mL}$ aliquots of Nanopure water were added. After shaking overhead for three days, the suspensions were centrifuged (Beckman Coulter Avanti J-E, $20000 \mathrm{~g}$ for 30 minutes), and the supernatant solutions were filtered with $0.2 \mu \mathrm{m}$ membrane filters. The resulting solutions were analyzed for $\mathrm{Br}$ by inductively coupled plasma mass spectrometry (ICP-MS) using a Perkin-Elmer SCIEX ICP-Mass Spectrometer ELAN DRC II.

\subsection{Multi-component transport modeling.}

The diffusion experiments were modeled with PHREEQC v3.0 in a 1D geometry using the multicomponent diffusion (MCD) capabilities of the code. Details of the system geometry are given in the Electronic Annex (Fig. EA-2). Relevant equations and numerical methods are described in detail elsewhere (Parkhurst and Appelo, 1999, 2013; Appelo and Wersin, 2007; Appelo et al., 2010). Self-diffusion coefficients in bulk liquid water for individual chemical species were taken from the PHREEQC.dat database.

A constant tracer concentration was assigned to the high concentration reservoir. The renewal of the electrolyte solution in the low concentration reservoir with each sampling event has a nonnegligible effect on the solute concentration gradients and, thus, on the recorded fluxes (Glaus et al., 2015). This effect was taken into account during the simulation by allowing tracers to accumulate as a function of time in two numerical cells: a first cell representing the low concentration reservoir, and a second cell representing a "dead volume" located between the clay sample and the low concentration reservoir (mimicking the tubing of the peristaltic pump). After each sampling event, the tracer concentration was reset to zero in the numeric cell representing the low concentration reservoir, but not in the cell representing the dead volume. As shown below, this approach allowed us to predict the impact of small variations in the sampling intervals on diffusive mass fluxes. 
1 In the following, the data are presented in terms of diffusive mass fluxes in order to comply with

2 the typical presentation style for diffusion data in the literature. No temperature correction was

3 done. Diffusion in the filters and in the dead volume at the end of the experimental device was

4 explicitly taken into account. Transport parameters for the filters were obtained from the

5 literature (Molera, 2002; Molera et al., 2003) as the same filters were used for the present study:

6 porosity $\theta_{f}=0.25$, geometrical factor $G_{f}=2.33$, height $=0.79 \mathrm{~mm}$. Molera and co-workers found

7 identical $G_{f}$ values for $\mathrm{Na}^{+}, \mathrm{Cs}^{+}$and $\mathrm{Sr}^{2+}$ diffusion; hence, we assumed that the filter diffusion

8 parameters were identical for all chemical species in our experiments.

9 The modeling strategy was similar to the one developed in Appelo et al. (2010). In the first step, $10 \mathrm{HTO}, \mathrm{Br}$, and Ca diffusion were modeled individually with the simple Fickian model (eqs 1-2) in 11 order to derive species-dependent values of $\alpha$ and $D_{\mathrm{e}}$. In a second step, pore scale models 12 proposed in previous studies (Fig. 1) were tested against our experimental data and compared 13 with our MD simulation results.

\section{2.3. Molecular dynamics simulations.}

15 Molecular dynamics (MD) simulations of a $\mathrm{Na}-\mathrm{Ca}-\mathrm{Cl}-\mathrm{Br}$ aqueous solution confined in a $31.5 \AA$ wide nanopore between parallel smectite basal surfaces were carried out in conditions that approximate the solid/water ratio and aqueous geochemistry of our adsorption and diffusion experiments. Our simulation methodology is known for accurate predictions of diffusion coefficients and activation energies of diffusion of water and sodium in smectite interlayer nanopores for pore widths ranging from 0.3 to $30 \AA$ and temperatures ranging from 278 to $353 \mathrm{~K}$ (Holmboe and Bourg, 2014). In brief, simulations were carried out with the program LAMMPS (Plimpton, 1995) using periodic boundary conditions. Inter-atomic interactions were described with the SPC/E model of liquid water (Berendsen et al., 1987), the CLAYFF model of mineralwater interactions (Cygan et al., 2004), the parameters of Joung and Cheatham (Joung and Cheatham, 2009) for the alkali and halide ions, and the parameters of Åvist (1990) for $\mathrm{Ca}^{2+}$. Water molecules were kept rigid using the SHAKE algorithm (Ryckaert et al., 1977). All clay mineral atoms were kept immobile except for structural $\mathrm{H}$ atoms. Production runs from two different initial configurations, differing only by their initial distribution of the interlayer ions, were carried out in the $N V T$ ensemble (constant composition, volume, and temperature) with a 1 fs time step for a total duration of 105 ns. The production runs were preceded by $1 \mathrm{~ns}$ of equilibration in the $N P T$ ensemble (at $P=1 \mathrm{bar}$ ) and $5 \mathrm{~ns}$ of equilibration in the $N V T$ ensemble. Comparison of the two production runs allowed us to verify that the equilibrium ion density profiles were not influenced by the initial distribution of the ions. Reported density profiles and diffusion coefficients are average values for the two production runs. Electrostatic and dispersion interactions beyond $12 \AA$ were computed with the particle-particle particle-mesh (PPPM) solver (Hockney and Eastwood, 1988; Isele-Holder et al., 2012). Two-dimensional diffusion coefficients $\left(D_{\text {pore }}\right)$ in the $x y$ plane of the interlayer nanopores were calculated with the well- 


$$
D_{\text {pore }}=\frac{1}{2 n} \lim _{\tau \rightarrow \infty} \frac{d\left\langle l^{2}\right\rangle}{d \tau}
$$

2 where $n=2$ for diffusion in the $x y$ plane and $\left\langle l^{2}\right\rangle$ is the mean-square displacement of the species 3 of interest as a function of time $\tau$. Three-dimensional diffusion coefficients were not calculated, 4 because the large shape ratio of clay interlayer nanopores (a few nanometers wide in the $z$ direction, but hundreds of nanometers wide in the $x y$ plane) renders diffusion in the $z$ direction essentially irrelevant to the objective of predicting macroscopic-scale diffusion coefficients. The infinite-time limit in the Einstein relation was evaluated using the slope $\left\langle l^{2}\right\rangle$ vs. $\tau$ for $\tau=150$ to $250 \mathrm{ps}$, as calculations using shorter probe time scales may not accurately reflect the infinite-time diffusive limit in clay interlayers (Bourg and Sposito, 2010; Holmboe and Bourg, 2014).

10 In order to calculate $D_{\text {pore }}$ as a function of distance from the surface, the pore was divided into $0.2 \AA$ thick slices parallel to the clay mineral surfaces. As the average residence time of individual water molecules or ions within each slice was only a fraction of $\tau$, the mean square displacement within each slice was analyzed by applying eq 8 to a "mended trajectory" constructed by appending all segments of trajectory data of the species of interest in each slice into a single pseudo-trajectory as described in the Electronic Annex.

The simulated system contained 180 clay mineral unit cells with an average unit cell formula of $\mathrm{Si}_{8}\left(\mathrm{Al}_{3.33} \mathrm{Mg}_{0.67}\right) \mathrm{O}_{20}(\mathrm{OH})_{4}, 116 \mathrm{Na}^{+}$ions, $4 \mathrm{Ca}^{2+}$ ions, $3 \mathrm{Cl}^{-}$ions, $1 \mathrm{Br}^{-}$ion, and 9000 water molecules (total of 34324 atoms) in a $93.305 \times 90.030 \times 40.913 \AA$ simulation cell (Fig. 2). The system was designed to approximate the conditions of the macroscopic diffusion experiment. The average unit cell formula used in our simulations represents a typical Wyoming-type montmorillonite similar to that of the clay used in the experiments (untreated Na$\left(\mathrm{Ca}_{0.52} \mathrm{Na}_{0.14} \mathrm{~K}_{0.01}\right)\left[\mathrm{Al}_{3.23} \mathrm{Fe}(\mathrm{III})_{0.42} \mathrm{Mg}_{0.56}\right]\left[\mathrm{Si}_{7.89} \mathrm{Al}_{0.11}\right] \mathrm{O}_{20}(\mathrm{OH})_{4}$, Mermut and Cano, 2001). The dry bulk density in our MD simulations $\left[\rho_{\mathrm{b}}=0.65 \mathrm{~kg} \cdot \mathrm{dm}^{-3}\right.$, calculated using a smectite particle thickness of $9.4 \AA$ and a clay mineral layer density of $2.84 \mathrm{~kg} \cdot \mathrm{dm}^{-3}$ (Bourg et al., 2006; Tournassat and Appelo, 2011)] was close to that used in the experiments. The small difference in density between the two systems (experimental diffusion cell and MD simulation cell) is accidental but only reinforces the main finding of our study: the MD simulations overestimate anion exclusion relative to the experiments, and they would overestimate anion exclusion even more strongly if they had been carried out with exactly the same solid-water ratio. The average composition of the nanopore water $\left(0.712 \mathrm{M} \mathrm{Na}^{+}, 0.247 \mathrm{M} \mathrm{Ca}^{2+}, 0.019 \mathrm{M} \mathrm{Cl}^{-}, 0.006 \mathrm{M} \mathrm{Br}^{-}\right)$was selected to approximate the expected composition in a real pore with the same width and surface charge density in equilibrium with a $0.1 \mathrm{M} \mathrm{NaCl}$ bulk aqueous solution with minor concentrations of $\mathrm{Ca}^{2+}$ and $\mathrm{Br}^{-}$, as in our macroscopic scale experiments. The average composition of the nanopore water was estimated using the Poisson-Boltzmann equation, as described in section 3.3.2. 


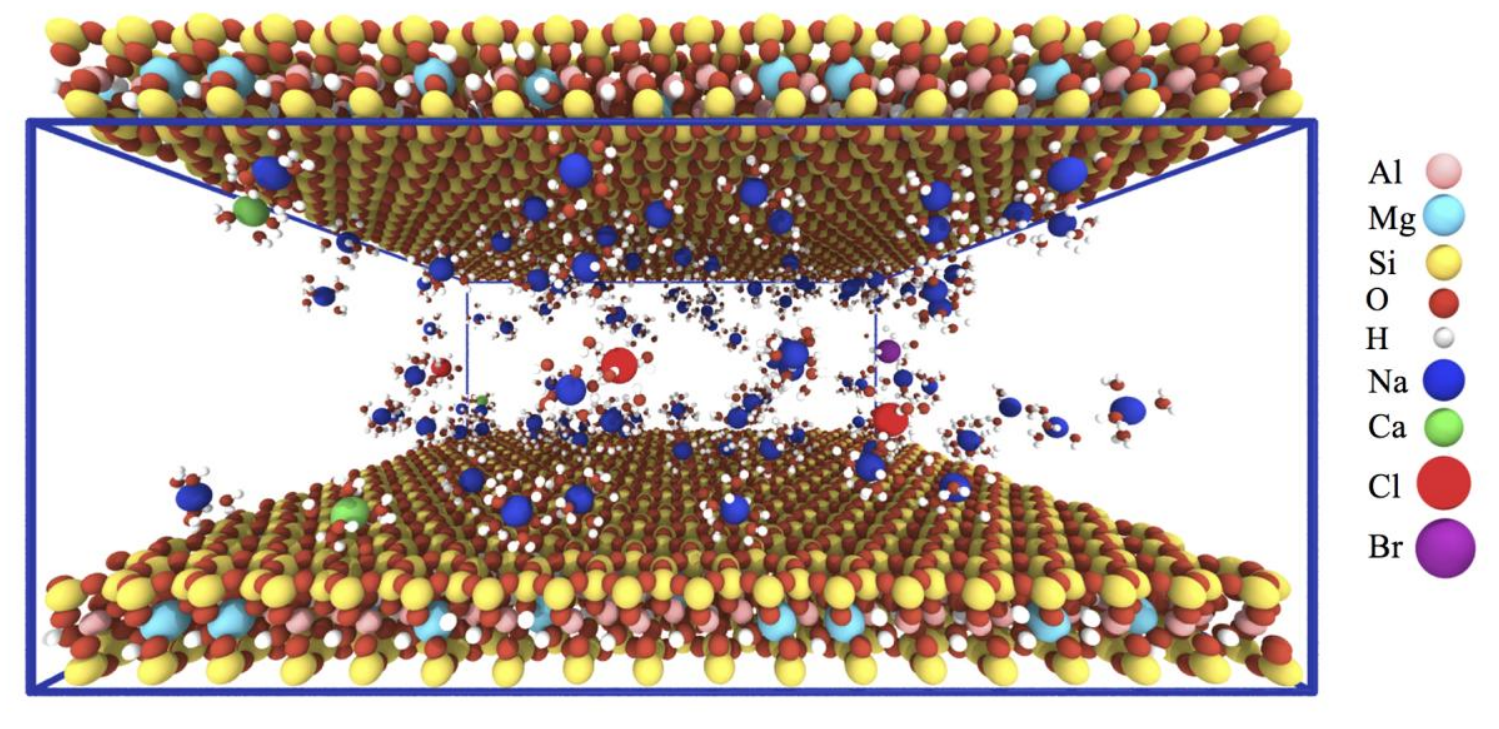

2 Fig. 2. Snapshot of our MD simulation cell showing the smectite clay layer and the $31.5 \AA$ wide 3 interlayer nanopore containing $\mathrm{Na}^{+}$(blue), $\mathrm{Ca}^{2+}$ (green), $\mathrm{Br}^{-}$(purple), and $\mathrm{Cl}^{-}$(red) ions with their 4 first hydration shell water molecules. Other water molecules are not shown. The clay mineral 5 structure contains $\mathrm{Si}$ (yellow), $\mathrm{Al}$ (pink), $\mathrm{Mg}$ (light blue), $\mathrm{O}$ (red), and $\mathrm{H}$ (white) atoms.

\section{3. Results}

\section{$7 \quad$ 3.1. Experimental results}

\subsubsection{Diffusion breakthrough curves}

9 Experimental data in tabulated form are provided in the Electronic Annex in order to allow other researchers to conduct their own model simulations of this experiment. Normalized mass flux densities reaching the low concentration reservoir $\left(J_{\mathrm{N}}\right.$ in $\left.\mathrm{m} \cdot \mathrm{day}^{-1}\right)$ were calculated with the 12 expression:

$$
J_{\mathrm{N}}=\frac{C_{\text {low }}}{C_{\text {high }}} \frac{V_{\text {low }}}{A \cdot \Delta t}
$$

13 where $C_{\text {low }}$ is the concentration of the species of interest measured in the low concentration 14 reservoir at a sampling event, $C_{\text {high }}$ is the constant concentration in the high concentration 15 reservoir, $\Delta t$ is the time interval since the previous sampling event (in days), $A$ is the cross 16 sectional area of the diffusion cell $\left(0.785 \mathrm{~cm}^{2}\right)$, and $V_{\text {low }}$ is the volume of the low-concentration 17 reservoir (about $20 \mathrm{~mL}$ ).

18 The low concentration reservoir solution was replaced frequently during the experiment to ensure 19 that $C_{\text {low }} / C_{\text {high }}<0.02$. However, it was not feasible to exchange the low concentration reservoir 20 solution on a perfectly even schedule. Thus, at steady state flux conditions, $C_{\text {low }}$ fluctuated 21 significantly from sample to sample, because $C_{\text {low }}$ increased with $\Delta t$ (Fig. 3). 
1 Normalized diffusion fluxes at steady state increased in the order of $J_{\mathrm{Br}}<J_{\mathrm{HTO}}<J_{\mathrm{Ca}}$, i.e., from 2 anion to neutral species to cation. This finding is in agreement with previously reported results. 3 Steady state diffusion was attained after a few days for HTO and $\mathrm{Br}$, and after one month for Ca. 4 A greater retardation of $\mathrm{Ca}$ breakthrough is expected based on the adsorption of $\mathrm{Ca}^{2+}$ onto 5 smectite clay surfaces.
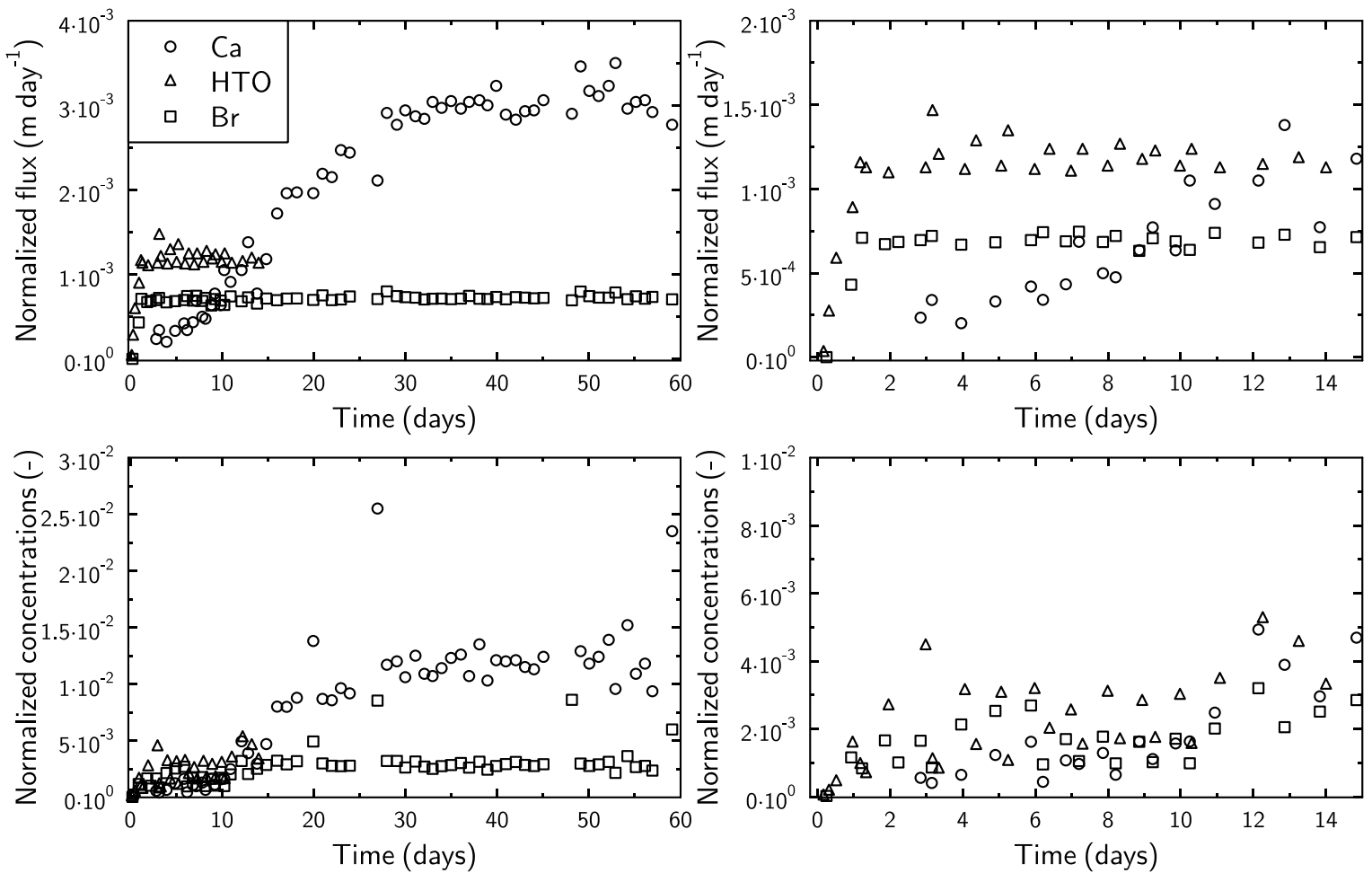

7 Fig. 3. Top: Comparison of normalized mass flux densities as a function of time for $\mathrm{Ca}$ (circles), 8 HTO (triangles), and $\mathrm{Br}$ (squares). Bottom: Comparison of normalized concentrations (same 9 symbols). Right figures show the results for the first 15 days of the diffusion experiments.

\section{3.1.2. Total porosity and anion accessible porosity from the static experiment}

11 The clay was compacted to a calculated dry bulk density $\rho_{\mathrm{b}}=0.79 \mathrm{~kg} \cdot \mathrm{dm}^{-3}$ based on the mass of 12 clay packed and the volume of the cell. The crystal density of clay mineral layers (or grain 13 density, $\rho_{\mathrm{g}}$ ) is about $2.84 \mathrm{~kg} \cdot \mathrm{dm}^{-3}$ (Bourg et al., 2006; Tournassat and Appelo, 2011). If we 14 neglect the small difference between the $\rho_{\mathrm{g}}$ values of clay mineral layers and impurities (mostly 15 fine grained quartz), the porosity of the material is given by:

$$
\theta=1-\frac{\rho_{\mathrm{b}}}{\rho_{\mathrm{g}}}
$$

16 which yields $\theta=0.72$. This value is in good agreement with the value determined by water loss 17 upon drying at $150{ }^{\circ} \mathrm{C}(\theta=0.74)$ after the static experiment. 
1 In the static experiment, the bromide concentration in both reservoirs was $8.5 \times 10^{-4} \mathrm{~mol} \cdot \mathrm{kg}_{\text {water }}{ }^{-1}$.

2 The leaching experiment yielded a bromide concentration value of $6.3 \times 10^{-4} \mathrm{~mol} \cdot \mathrm{kg}_{\text {water }}{ }^{-1}$ in the

3 clay plug. Based on these measurements, the bromide accessible (or effective) porosity equals

$474 \%$ of the total porosity, i.e., $\theta_{\mathrm{e}, \mathrm{Br}}=0.55$.

5 3.1.3. Specific surface charge and mean pore size

6 The total specific area of montmorillonite layers is $a_{\mathrm{s}}=770 \mathrm{~m}^{2} \cdot \mathrm{g}^{-1}$ (Bourg et al., 2006;

7 Tournassat and Appelo, 2011). The reported cation exchange capacity of SWy-2 montmorillonite

8 is on the order of 0.85 to $0.9 \mathrm{~mol}_{\mathrm{c}} \cdot \mathrm{kg}^{-1}$ (Duc et al., 2006; Tertre et al., 2011). Hence, it follows

9 that the surface charge density is about $\sigma_{0}=-0.11 \mathrm{C} \cdot \mathrm{m}^{-2}$.

10 If the pores are assumed to be slit-shaped and residual impurities (non-clay grains) are neglected,

11 the average pore width $h_{\text {pore }}$ can be calculated from the relation (Tournassat and Appelo, 2011;

12 Holmboe et al., 2012):

13 which yields a value of about $24 \AA$.

$$
h_{\text {pore }}=\frac{2 \cdot \theta}{\rho_{\mathrm{b}} a_{\mathrm{s}}}
$$

\section{3.2. Multi-component transport modeling with simple Fickian diffusion models (eq 2)}

\section{3.2.1. Diffusion coefficients}

16 HTO. In through-diffusion experiments such as those carried out in the present study, the effective diffusion coefficient $D_{\mathrm{e}}$ determines the steady-state flux, whereas the ratio $D_{\mathrm{e}} / \alpha$ determines the duration of the initial transient-state regime. Our steady-state diffusion data yield $D_{\text {e,HTO }}=7.3 \times 10^{-11} \mathrm{~m}^{2} \cdot \mathrm{s}^{-1}$ based on eq 2 , in agreement with previous values obtained under similar conditions of salinity and compaction (Tachi and Yotsuji, 2014). The transient-state period in our experiments was too brief to precisely quantify $\alpha$. However, previous studies indicate that $\alpha=\theta$ in the case of water diffusion in water-saturated bentonite. The model prediction with $D_{\mathrm{e}, \mathrm{HTO}}=$ $7.3 \times 10^{-11} \mathrm{~m}^{2} \cdot \mathrm{s}^{-1}$ and $\alpha=\theta=0.72$ is consistent with our experimental results (Fig. 4).

According to eq 4, the model prediction in Fig. 4 implies that $1 / G_{\text {HTO }}=0.047$ if $\theta=0.72$. [We note, in passing that the calculated value of $1 / G_{\mathrm{HTO}}$ depends on the value selected for $D_{0, \mathrm{HTO}}$, which is not provided in the PHREEQC database. Mills (1973) reported a value of $2.24 \times 10^{-9}$ $\mathrm{m}^{2} \cdot \mathrm{s}^{-1}$ for the diffusion of $\mathrm{HTO}$ in $\mathrm{H}_{2} \mathrm{O}$ at $298 \mathrm{~K}$. However, other $D$ values used in PHREEQC are based on the compilation of Li and Gregory (1974), in which $D_{0, \mathrm{HTO}}=2.13 \times 10^{-9} \mathrm{~m}^{2} \cdot \mathrm{s}^{-1}$ at 298 $\mathrm{K}$, as measured by Simpson and Carr (1958). For consistency with our PHREEQC calculations, our other calculations reported hereafter are based on a value of $D_{0, \mathrm{HTO}}=2.13 \times 10^{-9} \mathrm{~m}^{2} \cdot \mathrm{s}^{-1}$.] An equally good fit can be obtained with lower or higher porosity values and corresponding lower and higher values for $G_{\mathrm{HTO}}$, because the value of $\alpha$ is not precisely constrained by our experimental data. Therefore, the precision of our fitted $G$-value is inherently limited by the 
1 on the dry bulk density in our diffusion experiments; $\theta=0.74$ based on the water content in our

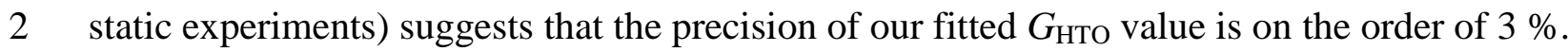

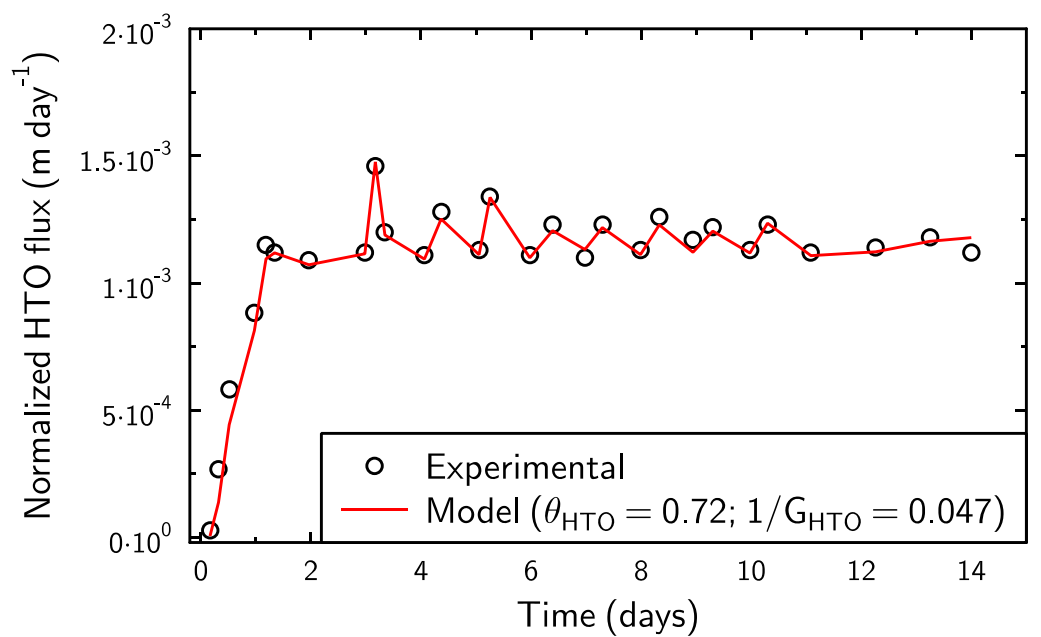

4 Fig. 4. HTO mass flux density as a function of time. Open circles: Experimental data. Full line: 5 Simple Fickian model with $\alpha=0.72$ and $D_{\mathrm{e}, \mathrm{HTO}}=7.3 \times 10^{-11} \mathrm{~m}^{2} \cdot \mathrm{s}^{-1}$.

6 Bromide. For Br, application of eq 2 to our diffusion results yields $D_{\mathrm{e}, \mathrm{Br}}=4.4 \times 10^{-11} \mathrm{~m}^{2} \cdot \mathrm{s}^{-1}$, a 7 value larger than that obtained by Tachi et al. (2014) but consistent with other studies (Molera et 8 al., 2003; Van Loon et al., 2007). As in the case of HTO, the transient-state period in our 9 experiments was too short to precisely constrain $\alpha$. However, our static experiments (section 10 3.1.2) indicate that $\alpha=\theta_{\mathrm{e}, \mathrm{Br}}=0.55$ under the conditions of our diffusion experiments. Model 11 predictions calculated with eq 2 with $\alpha=0.55$ and $D_{\mathrm{e}, \mathrm{Br}}=4.4 \times 10^{-11} \mathrm{~m}^{2} \cdot \mathrm{s}^{-1}$ are consistent with our 12 diffusion results, as shown in Fig. 5. According to eq 6 and based on a self-diffusion coefficient 13 for $\mathrm{Br}^{-}$of $2 \times 10^{-9} \mathrm{~m}^{2} \cdot \mathrm{s}^{-1}$ ( $\mathrm{Li}$ and Gregory, 1974), these values imply that $1 / G_{\mathrm{Br}}=0.040$. Hence, 14 the geometric factor associated with $\mathrm{Br}^{-}$diffusion is either identical or slightly higher than in the 15 case of HTO, in agreement with other studies of water and anion diffusion (Glaus et al., 2010).

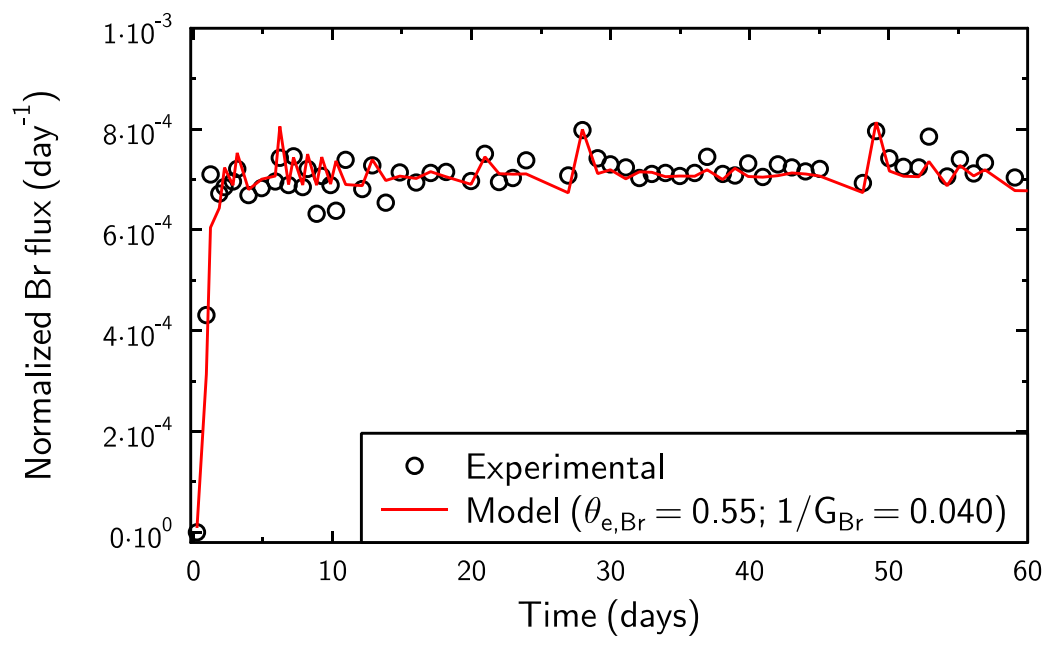


1 Fig. 5. Br mass flux density as a function of time. Open circles: Experimental data. Full line:

2 Simple Fickian model with $\alpha=0.55$ and $D_{\mathrm{e}, \mathrm{Br}}=4.4 \times 10^{-11} \mathrm{~m}^{2} \cdot \mathrm{s}^{-1}$.

3 Calcium. For $\mathrm{Ca}^{2+}$, a good fit to our diffusion results based on eq 2 was obtained with fitted 4 values of $D_{\mathrm{e}, \mathrm{Ca}}=2.06 \times 10^{-10} \mathrm{~m}^{2} \cdot \mathrm{s}^{-1}$ and $\alpha=63$ (Fig. 6). Based on eq 3 and $\rho_{\mathrm{b}}=0.79 \mathrm{~kg} \cdot \mathrm{dm}^{-3}$, this 5 corresponds to a $K_{D}$ value of $\sim 79 \mathrm{dm}^{3} \cdot \mathrm{kg}^{-1}$. If we apply eq 4 with $\theta=0.72$ and $D_{0, \mathrm{Ca}}=7.93 \times 10^{-}$ $6{ }^{10} \mathrm{~m}^{2} \cdot \mathrm{s}^{-1}$, our calculated $D_{\mathrm{e}, \mathrm{Ca}}$ value yields $1 / G_{\mathrm{Ca}}=0.36$. The value of $1 / G_{\mathrm{Ca}}$ is an order of 7 magnitude higher than $1 / G_{\mathrm{Br}}$ and $1 / G_{\mathrm{HTO}}$, indicating that $\mathrm{Ca}$ diffusion is enhanced by a factor of 8 ten compared to the diffusion of $\mathrm{HTO}$ or $\mathrm{Br}$.

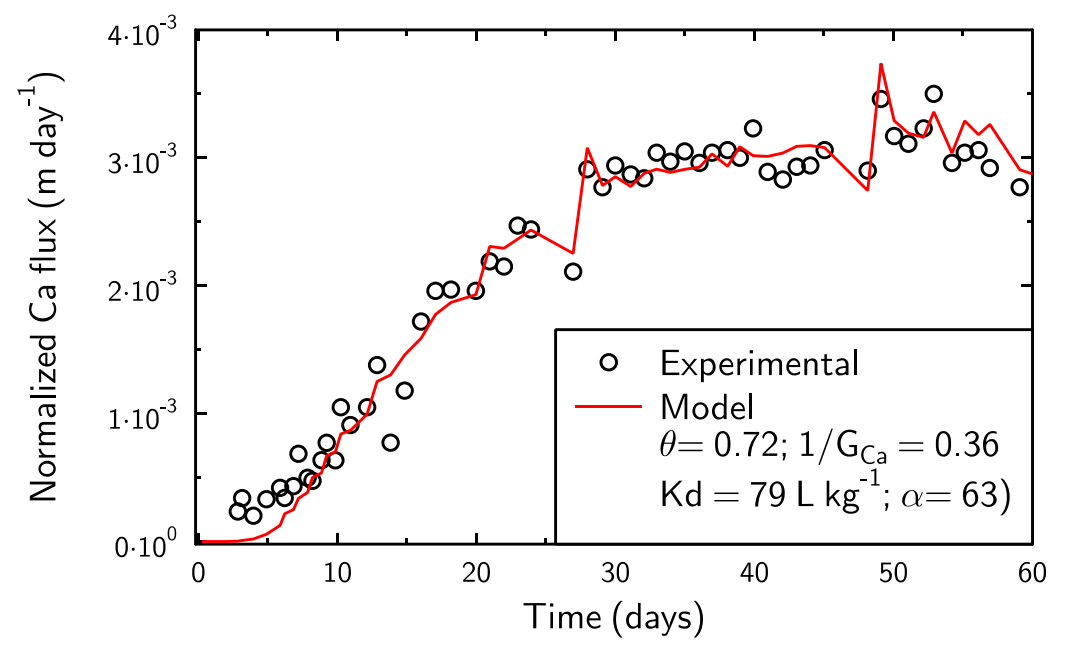

10 Fig. 6. Ca mass flux density as a function of time. Open circles: Experimental data. Full line: 11 Simple Fickian model with $\alpha=63$ and $D_{\mathrm{e}, \mathrm{Ca}}=2.0 \times 10^{-10} \mathrm{~m}^{2} \cdot \mathrm{s}^{-1}$.

12 Previous studies indicate that the cause of the rapid diffusion of $\mathrm{Ca}^{2+}$ may be more accurately 13 represented using eq 7 (without making any assumptions about the microscopic scale basis of the 14 "surface diffusion" coefficient $D_{\mathrm{s}}$ ). If we apply eq 7, the $D_{\mathrm{e}, \mathrm{Ca}}$ value used to obtain the model 15 prediction in Fig. 6 is consistent with $1 / G_{\mathrm{Ca}}=1 / G_{\mathrm{HTO}}=0.047$ with a fitted value of $D_{\mathrm{s}, \mathrm{Ca}}=2.82 \times$ $10^{-12} \mathrm{~m}^{2} \cdot \mathrm{s}^{-1}$. If we interpret this value with the relation $D_{\mathrm{s}}=\mu_{\mathrm{s}} D_{0} / G$, where $\mu_{\mathrm{s}}$ is the relative mobility of adsorbed cations (Gimmi and Kosakowski, 2011), our calculated values of $1 / G_{\mathrm{Ca}}$ and $D_{\mathrm{s}, \mathrm{Ca}}$ yield $\mu_{\mathrm{s}}=0.076$. For comparison, Gimmi and Kosakowski (2011) reported $\mu_{\mathrm{s}} \sim 0.1$ for $\mathrm{Ca}^{2+}$ based on their compilation of previous studies of diffusion in clayey media. In short, our experimental results are consistent with previous data suggesting that adsorbed $\mathrm{Ca}^{2+}$ ions diffuse, on average, roughly $90 \%$ slower than "free" (non-adsorbed) $\mathrm{Ca}^{2+}$ ions, after accounting for 22 tortuosity.

\subsubsection{Lessons learned from simple Fickian models}

24 The present work demonstrates the ability of reactive transport modeling to reduce the uncertainty of calculated transport parameters by identifying the cause of data fluctuation, while taking into account the complex geometry of the experimental system (clay, filters, dead- 
1 volumes) and the timing of sampling events. Figures 4 and 5 clearly show that the fluctuations in 2 the measured mass fluxes in our experiments are primarily due to the sampling procedure and not

3 to other factors such as analytical uncertainties, even though solute concentrations in the low 4 concentration reservoirs were never greater than $2 \%$ of the concentration in the high 5 concentration reservoir.

\section{3.3. Molecular dynamics simulations}

\section{3.3.1. Average density profiles for water and ions}

8 Molecular dynamics simulations were carried out to examine adsorption and diffusion of water,

$9 \mathrm{Br}^{-}$, and $\mathrm{Ca}^{2+}$ at the scale of an individual pore in conditions that mimic the solid-water ratio and 10 aqueous geochemistry of our diffusion experiments (Fig. 2). Simulation predictions of the 11 average density of ions and water as a function of distance from the clay mineral surface are 12 shown in Fig. 7. Despite significant methodological differences, our simulation results are 13 broadly consistent with those obtained in our previous study focusing on $\mathrm{Na}-\mathrm{Ca}-\mathrm{Cl}$ solutions at 14 higher salinities (0.3 to $1.8 \mathrm{~mol}_{\mathrm{c}} \cdot \mathrm{dm}^{-3}$ ) in 6-nm-wide clay interlayer nanopores (Bourg and 15 Sposito, 2011). Our MD simulations predict the existence of three ordered water layers at $z=6.1$, 169.5 , and $12.4 \AA$ (where $z=0$ is the mid-plane of the clay mineral particle). The distance between 17 the water density peaks is close to the diameter of a water molecule, indicating that the water 18 layering originates primarily from steric packing at the clay mineral-water interface.

19

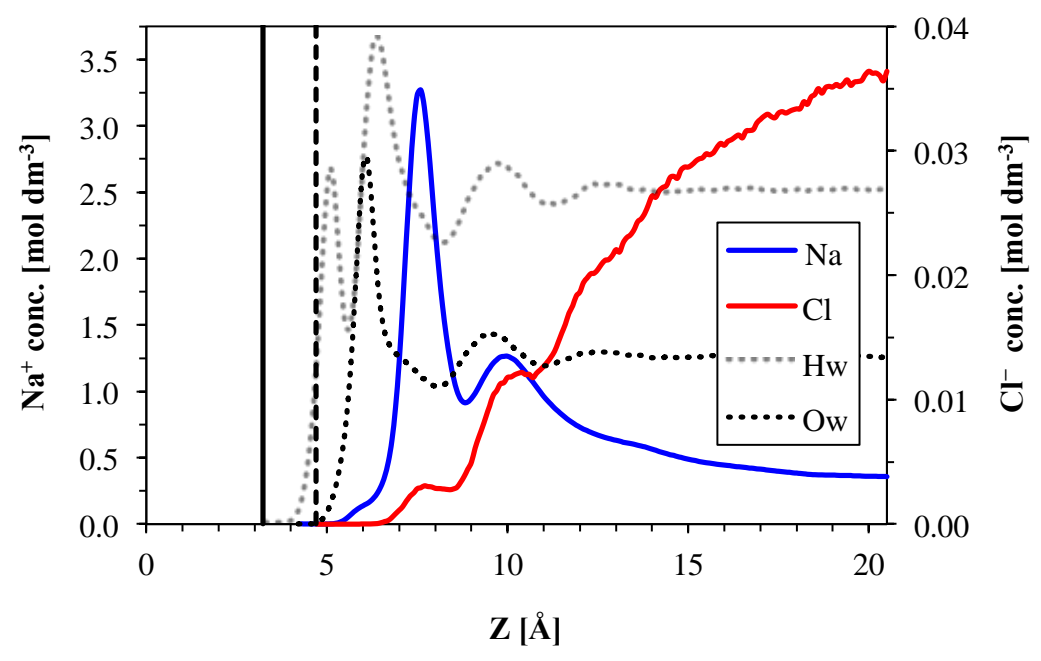



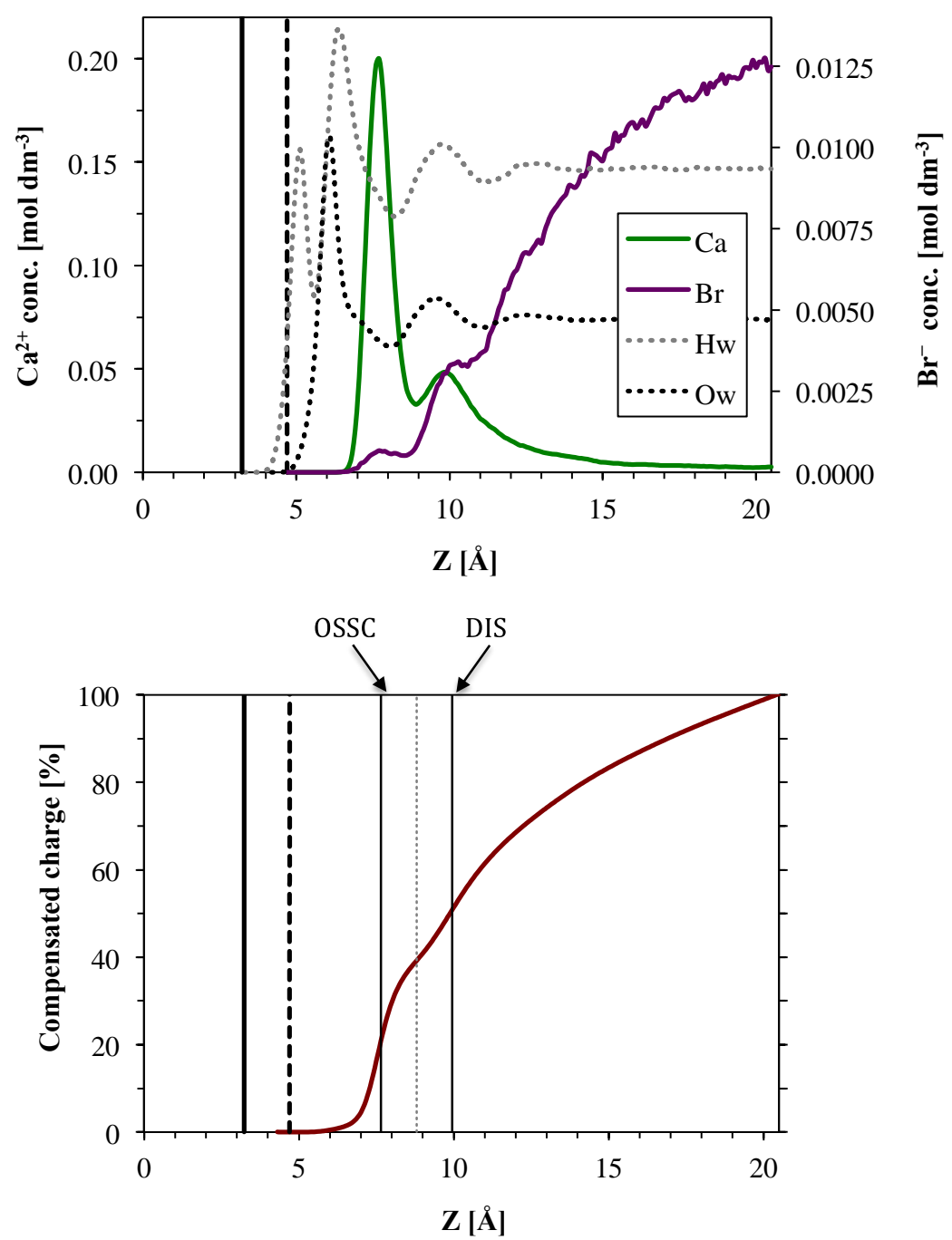

10 Fig. 7. Molecular dynamics simulation predictions of the average density profiles of water and 11 ions as a function of distance in the direction normal to the clay mineral surface, from the mid12 plane of the clay mineral layer $(z=0 \AA)$ to the mid-plane of the nanopore $(z=20.45 \AA)$. Vertical 13 lines show the location of the plane of surface $\mathrm{O}$ atoms (solid line, $z=3.23 \AA$ ) and the location of 14 the Gibbs dividing surface of liquid water (dashed line, $z=4.7 \AA$ ). Solid curves show the density 15 profiles of $\mathrm{Na}^{+}$and $\mathrm{Cl}^{-}$(upper figure) and $\mathrm{Ca}^{2+}$ and $\mathrm{Br}^{-}$(middle figure), using a different vertical 16 scale for each ion. Dotted black and gray lines depict the density profiles of water $\mathrm{O}(\mathrm{Ow})$ and $\mathrm{H}$ 17 (Hw) atoms with an arbitrary vertical scale. The bottom figure shows the cumulative percentage 18 of surface charge compensated by EDL ions as a function of distance from the clay mineral 19 surface, with vertical lines indicating the density peaks of outer-sphere surface complexes 20 (OSSC) and diffuse ion swarm (DIS) cations, respectively.

21 Ion density profiles show that $\mathrm{Na}^{+}$and $\mathrm{Ca}^{2+}$ are attracted to, and $\mathrm{Cl}^{-}$and $\mathrm{Br}^{-}$are repulsed from, the 22 vicinity of the clay mineral surface, as expected from the negative structural charge of the clay 23 mineral layer. For all four ionic species, the density profiles show two peaks near the clay 24 mineral surface: a first peak at $z=(7.65 \pm 0.1) \AA$ (for all four ions) and a second peak at $z=(9.95$ 
$1 \pm 0.1) \AA$ (for cations) or $(10.35 \pm 0.1) \AA$ (for anions). The coincidence of the cation and anion

2 density peaks suggests that peak positions may be determined by solvent structure effects such as

3 ion solvation or water density layering. In the context of the well-known triple-layer model

4 (Davis et al., 1978), the cation density peaks reflect adsorption as outer-sphere surface complexes

5 (OSSC) and in the diffuse ion swarm (DIS). The Stern layer contains $37 \%$ to $49 \%$ of $\mathrm{Na}^{+}$ions

6 and $58 \%$ to $72 \%$ of $\mathrm{Ca}^{2+}$ ions and screens 39 to $51 \%$ of the surface charge, depending on

7 whether the outer boundary of the Stern layer is identified with the DIS peak or with the density

8 minimum between the OSSC and DIS peak.

9 Average ion concentrations in the mid-plane of the nanopore (Table 1) show that water in the 10 mid-plane contains significantly more moles of cationic charge $\left(q_{+}=0.366 \mathrm{~mol}_{\mathrm{c}} \cdot \mathrm{dm}^{-3}\right)$ than 11 moles of anionic charge $\left(q_{-}=0.048 \mathrm{~mol}_{\mathrm{c}} \cdot \mathrm{dm}^{-3}\right)$. This indicates that the EDLs formed on the two 12 clay mineral surfaces overlap in the center of the nanopore, a phenomenon that strongly 13 influences clay swelling mechanics (Gonçalvès et al., 2007) and ionic mass fluxes in clayey 14 media (Kemper and Rollins, 1966; Neuzil and Provost, 2009).

\subsubsection{Composition of bulk liquid water in equilibrium with the simulated nanopore}

16 We can estimate the composition of a fictitious bulk liquid water reservoir in equilibrium with our nanopore in three ways. A first approach consists in applying a Boltzmann relation between concentrations at the interlayer mid-plane $\left(C_{i, \text { mid-plane }}\right)$ and in the bulk solution $\left(C_{i, \text { bulk }}\right.$ in mol $\left.\mathrm{dm}^{-3}\right)$ :

$$
C_{i, \text { mid-plane }}=C_{i, \text { bulk }} e^{\frac{-z_{i} F \psi_{\text {mid-plane }}}{R T}}
$$

20 along with a charge-balance relation in the fictitious bulk aqueous solution:

$$
\sum_{i} z_{i} C_{i, \text { bulk }}=0
$$

21 where $z_{i}$ is the valence of the ion $i$ of interest, $F$ is the Faraday constant $\left(96485 \mathrm{C} \cdot \mathrm{mol}^{-1}\right), T$ is 22 absolute temperature $(\mathrm{K}), R$ the gas constant $\left(8.314 \mathrm{~J} \cdot \mathrm{mol}^{-1} \cdot \mathrm{K}^{-1}\right)$, and $\psi_{\text {mid-plane }}$ is the electrostatic 23 potential at the mid-plane of the nanopore $(\mathrm{V})$.

24 A second approach consists in applying eq 13 along with a Boltzmann relation between the 25 average concentrations in the entire nanopore $\left(C_{i, \text { pore }}\right)$ and the fictitious solution:

$$
C_{i, \mathrm{pore}}=C_{i, \mathrm{bulk}} e^{\frac{-z_{i} F \psi_{\text {pore }}}{R T}}
$$

where $\psi_{\text {pore }}$ is an effective "mean electrostatic potential" in the nanopore (V). This approach corresponds to the one used in the LRC and BK models (Fig. 1).

A third approach consists in solving the full Poisson-Boltzmann (PB) equation numerically while adjusting the chemical composition of the fictitious bulk solution to match the MD concentration profiles (Fig. 8; Jardat et al., 2009). For this calculation, the surface charge density was set to $0.114 \mathrm{C} \cdot \mathrm{m}^{-2}$. Furthermore, a distance of closest approach of ions to the clay mineral surface 
1 (equal to $2.85 \AA$, if the location of the clay mineral-water interface is identified with the Gibbs 2 dividing surface of water) was applied to reproduce the position of the first adsorption peak $(z=$ 3 (7.65 \pm 0.1$) \AA)$, which is the same for all ions. Cation concentrations in the fictitious bulk 4 solution were adjusted to match the MD concentration profiles. Anion concentrations in the 5 fictitious reservoir are constrained by eq 13 and the relation $C_{\mathrm{Cl}, \text { bulk }}=3 \times C_{\mathrm{Br} \text {,bulk }}$. This approach is 6 analogous to the one used in the GRR and TY models (Fig. 1), except that these models assume 7 that the distance of closest approach of ions to the clay mineral surface is $0 \AA$ (versus $2.85 \AA$ in 8 our MD simulations).
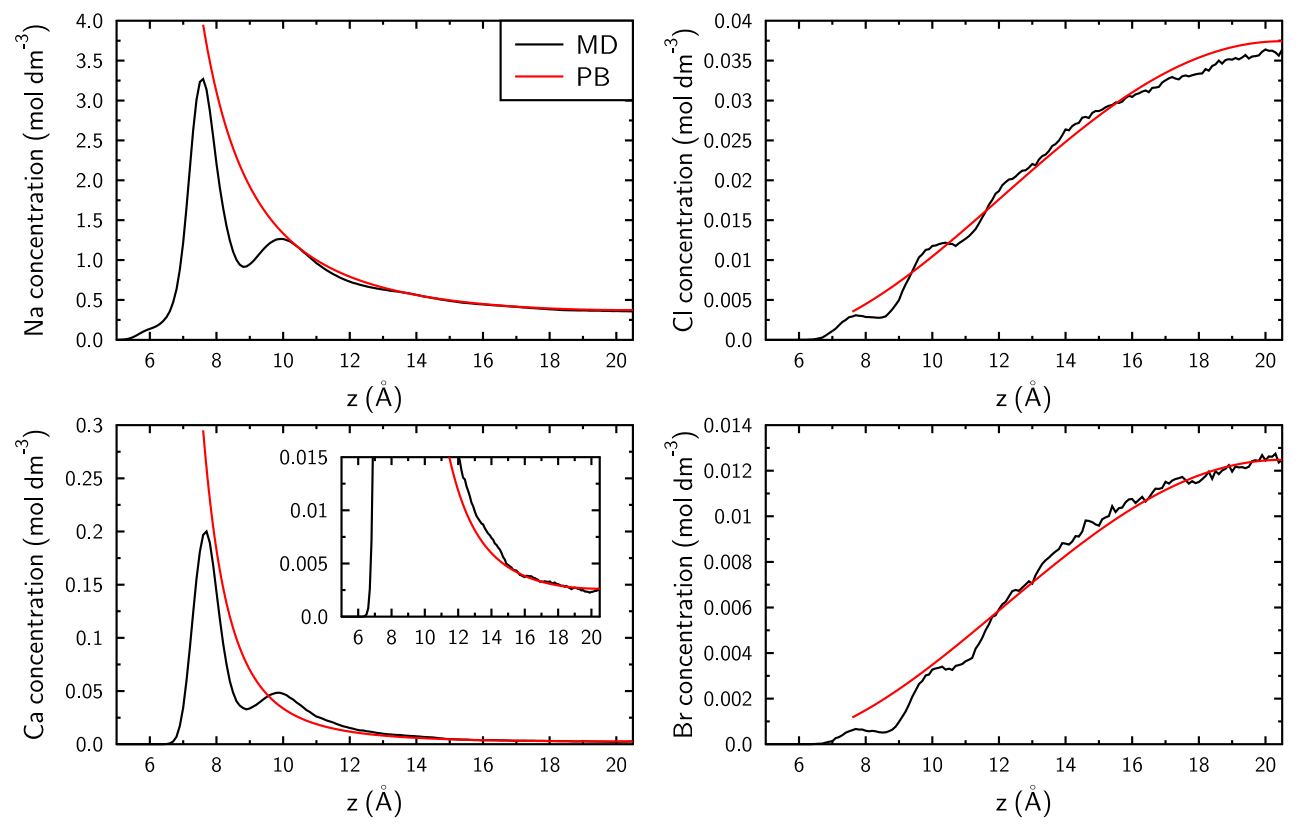

10 Fig. 8. Cation and anion density profiles as a function of distance from the clay mineral surface: MD simulation results (black lines) and Poisson-Boltzmann model calculation (red lines).

13 Table 1. Molecular dynamics simulation predictions of the average ion concentration in the entire 14 pore $\left(C_{i, \text { pore }}\right)$ and in the mid-plane of the pore $\left(C_{i, \text { mid-plane }}\right)$. Ion concentrations in a fictitious bulk 15 water reservoir $\left(C_{i, \text { bulk }}\right)$ in equilibrium with the pore were calculated using eq 12 , eq 14 , or the 16 Poisson-Bolzmann equation.

\begin{tabular}{c|c|cccc} 
Row No. & & $\mathrm{Br}$ & $\mathrm{Cl}$ & $\mathrm{Ca}$ & $\mathrm{Na}$ \\
\hline & & \multicolumn{4}{|c}{ MD simulation prediction } \\
1 & $C_{i, \text { pore }}\left(\mathrm{mol} \cdot \mathrm{dm}^{-3}\right)$ & $6.2 \cdot 10^{-3}$ & $1.9 \cdot 10^{-2}$ & $2.5 \cdot 10^{-2}$ & $7.2 \cdot 10^{-1}$ \\
2 & $C_{i, \text { mid-plane }}\left(\mathrm{mol} \cdot \mathrm{dm}^{-3}\right)$ & $1.3 \cdot 10^{-2}$ & $3.6 \cdot 10^{-2}$ & $2.4 \cdot 10^{-3}$ & $3.6 \cdot 10^{-1}$ \\
\hline & & \multicolumn{4}{|c}{ eq 12} \\
3 & $C_{i, \text { bulk }}\left(\mathrm{mol} \cdot \mathrm{dm}^{-3}\right)$ & $3.4 \cdot 10^{-2}$ & $9.8 \cdot 10^{-2}$ & $3.2 \cdot 10^{-4}$ & $1.3 \cdot 10^{-1}$ \\
\hline & & \multicolumn{4}{|c}{ eq 14}
\end{tabular}




\begin{tabular}{c|c|cccc}
4 & $C_{i, \text { bulk }}\left(\mathrm{mol} \cdot \mathrm{dm}^{-3}\right)$ & $3.4 \cdot 10^{-2}$ & $1.0 \cdot 10^{-1}$ & $8.4 \cdot 10^{-4}$ & $1.3 \cdot 10^{-1}$ \\
\hline & & \multicolumn{4}{|c}{ Poisson-Boltzmann equation } \\
5 & $C_{i, \text { pore }}\left(\mathrm{mol} \cdot \mathrm{dm}^{-3}\right)^{*}$ & $5.7 \cdot 10^{-3}$ & $1.7 \cdot 10^{-2}$ & $1.9 \cdot 10^{-2}$ & $6.5 \cdot 10^{-1}$ \\
6 & $C_{i, \text { bulk }}\left(\mathrm{mol} \cdot \mathrm{dm}^{-3}\right)$ & $3.4 \cdot 10^{-2}$ & $1.0 \cdot 10^{-1}$ & $3.5 \cdot 10^{-4}$ & $1.4 \cdot 10^{-1}$ \\
\hline & & \multicolumn{4}{|c}{ Adsorption or negative adsorption } \\
7 & $m_{i}\left(\mathrm{~mol} \cdot \mathrm{kg}^{-1}\right)^{* *}$ & $-3.3 \cdot 10^{-2}$ & $-1.0 \cdot 10^{-1}$ & $2.9 \cdot 10^{-2}$ & $6.9 \cdot 10^{-1}$ \\
8 & $\theta_{\mathrm{e}} / \theta(-)^{* *}$ & 0.18 & 0.18 & n.a. & n.a. \\
9 & $K_{\mathrm{D}, i}\left(\mathrm{dm}^{3} \cdot \mathrm{kg}^{-1}\right)^{* *}$ & n.a. & n.a. & 83 & 5.1 \\
\hline
\end{tabular}

* normalized to the total pore size

** Calculated using values from rows 1 and $6, M=0.84 \mathrm{~kg}_{\text {clay }} \cdot \mathrm{kg}_{\text {water }}{ }^{-1}$, and eqs 15-17. Similar values are obtained by combining our MD simulation predictions and the $C_{i, \text { bulk }}$ values calculated with eq 12 .

The excellent agreement for anion profiles between MD calculations and PB predictions justifies the use of the PB equation (without a Stern layer and with a distance of closest approach of ions to the clay mineral surface equal to $2.85 \AA$ ) to estimate the anion accessible porosity in pores of similar size, and for similar ionic strengths and solution compositions. A reasonable agreement between MD results and $\mathrm{PB}$ model predictions was also found for the mean concentrations of cations in the pore (23\% difference for $\mathrm{Ca}^{2+}$, and $9 \%$ difference for $\mathrm{Na}^{+}$). The model based on a Boltzmann factor between the mid-plane of the pore and the fictitious bulk water reservoir (eq 12) gives essentially the same results as the full solution to the PB equation. The model based on a Boltzmann factor between the average pore fluid concentrations and the fictitious bulk water reservoir (eq 14, the mean potential model used in the LRC and BK models, Fig. 1) predicts similar concentrations for monovalent ions but it underestimates the ratio $C_{i, \text { pore }} / C_{i, \text { bulk }}$ by a factor of about 2.5 in the case of $\mathrm{Ca}^{2+}$.

\subsubsection{Molecular dynamics simulation predictions for anion-accessible porosities, $K_{D}$ values, and} pore scale diffusion coefficients

The values of $C_{i \text {,pore }}$ and $C_{i \text {,bulk }}$ in Table 1 allow us to quantify several ion adsorption (or negative adsorption) coefficients at the nanopore scale. The quantity of adsorbed solute per mass of clay, $m_{i}$, can be calculated according to the relation:

$$
m_{i}=\frac{C_{i, \text { pore }}-C_{i, \text { bulk }}}{M}
$$

where $M$ is the mass of clay per volume of pore water. For this purpose, the value of $M(M=0.84$ $\left.\mathrm{kg}_{\text {clay }} \cdot \mathrm{kg}_{\text {water }}{ }^{-1}\right)$ was calculated as the ratio of the dry bulk density used in MD simulations $(0.65$ $\mathrm{kg}_{\text {clay }} \cdot \mathrm{dm}^{-3}$, section 3.3) over the mass/volume of water $\left[(1-0.65) / 2.84=0.77 \mathrm{~kg}_{\text {water }} \cdot \mathrm{dm}^{-3}\right]$, while using a clay mineral layer density value of $2.84 \mathrm{~kg} \cdot \mathrm{dm}^{-3}$. The $m_{i}$ values given in Table 1 were 
1 calculated using the $C_{i \text {,pore }}$ values from MD predictions (row 1, Table 1) and $C_{i, \text { bulk }}$ values 2 obtained from the resolution of the PB equation (row 6, Table 1), which are consistent with our 3 MD simulation results.

4 Alternatively, adsorption can be expressed as a relative anion-accessible porosity $\left(\theta_{\mathrm{e}} / \theta\right)$ in the 5 case of anions

$$
\frac{\theta_{\mathrm{e}}}{\theta}=\frac{C_{i, \mathrm{pore}}}{C_{i, \mathrm{bulk}}}
$$

or as a linear adsorption coefficient $\left(K_{\mathrm{D}, \mathrm{i}}\right)$ in the case of cations

$$
K_{D, i}=\frac{m_{\mathrm{i}}}{C_{i, \text { bulk }}}
$$

8 Predicted $K_{\mathrm{D}, \mathrm{i}}$ values for $\mathrm{Na}^{+}$and $\mathrm{Ca}^{2+}$ in our nanopore are consistent with macroscopic scale 9 experimental values reported at similar conditions (Molera and Eriksen, 2002; Wang and Liu, 10 2004; Tachi and Yotsuji, 2014; Bourg and Tournassat, 2015). However, our predicted value of 11 the relative anion-accessible porosity $\left(\theta_{\mathrm{e}} / \theta\right)$ in our nanopore is much lower than the values 12 obtained in our experiments (section 3.1.2) or in other experimental studies at similar conditions 13 of salinity and dry bulk density (Molera et al., 2003; Tachi and Yotsuji, 2014; Bourg and 14 Tournassat, 2015).

15 Molecular dynamics simulation predictions of the diffusion coefficients of water and ions in bulk 16 liquid water $\left(D_{\text {bulk }}\right)$ and in our clay interlayer nanopore $\left(D_{\text {pore }}\right)$, reported in Table 2 , indicate that 17 all species diffuse more slowly in the nanopore than in bulk liquid water. The influence of 18 confinement, quantified by the factor $q_{\text {nano }}=D_{\text {pore }} / D_{\text {bulk }}$, is essentially identical for all species except $\mathrm{Ca}^{2+}$ (Table 2). This difference arises from the fact that calcium is strongly concentrated near the clay mineral surface (even more strongly than $\mathrm{Na}^{+}$), where water and solutes tend to diffuse more slowly. Simulation predictions of the self-diffusion coefficient of water $\mathrm{O}$ atoms as a function of distance from the surface (Fig. 9) indicate that in the region between the first and second water layers, where a significant fraction of the cations are adsorbed as OSSC, water diffuses roughly $33 \%$ more slowly than bulk liquid water.

Table 2. Molecular dynamics simulation predictions of the average diffusion coefficients of ions and water in the clay nanopores $\left(D_{\text {pore }}\right)$ and in bulk liquid water $\left(D_{\text {bulk }}\right)$. Diffusion coefficients were calculated with eq 8 using either $n=2$ and the mean-square displacement in the $x y$ plane (in the case of $D_{\text {pore }}$ ), or $n=3$ and the mean-square displacement in $x y z$ space (in the case of $D_{\text {bulk }}$ ). Values of $D_{\text {bulk }}$ are corrected for a well-established artifact of the periodic boundary conditions that causes a simulation cell size dependence of $D$ in MD simulations of bulk fluids; for $D_{\text {pore }}$ no correction is needed as shown in our previous study (Holmboe and Bourg, 2014). The last row shows that $q_{\text {nano }}=D_{\text {pore }} / D_{\text {bulk }}$ is $<1$ for all species (even anions).
$\mathrm{Br}$
$\mathrm{Cl}$
$\mathrm{Ca}$
$\mathrm{Na}$
$\mathrm{H}_{2} \mathrm{O}$ 


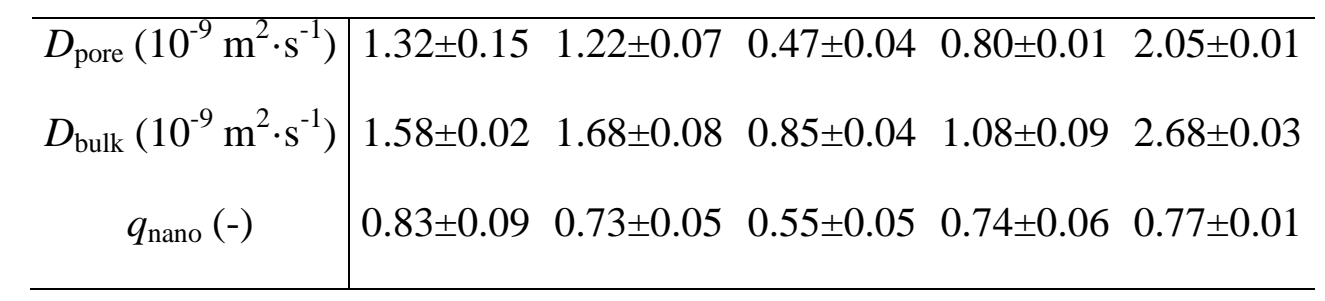

1

2

3

4

5

6

7

8

9
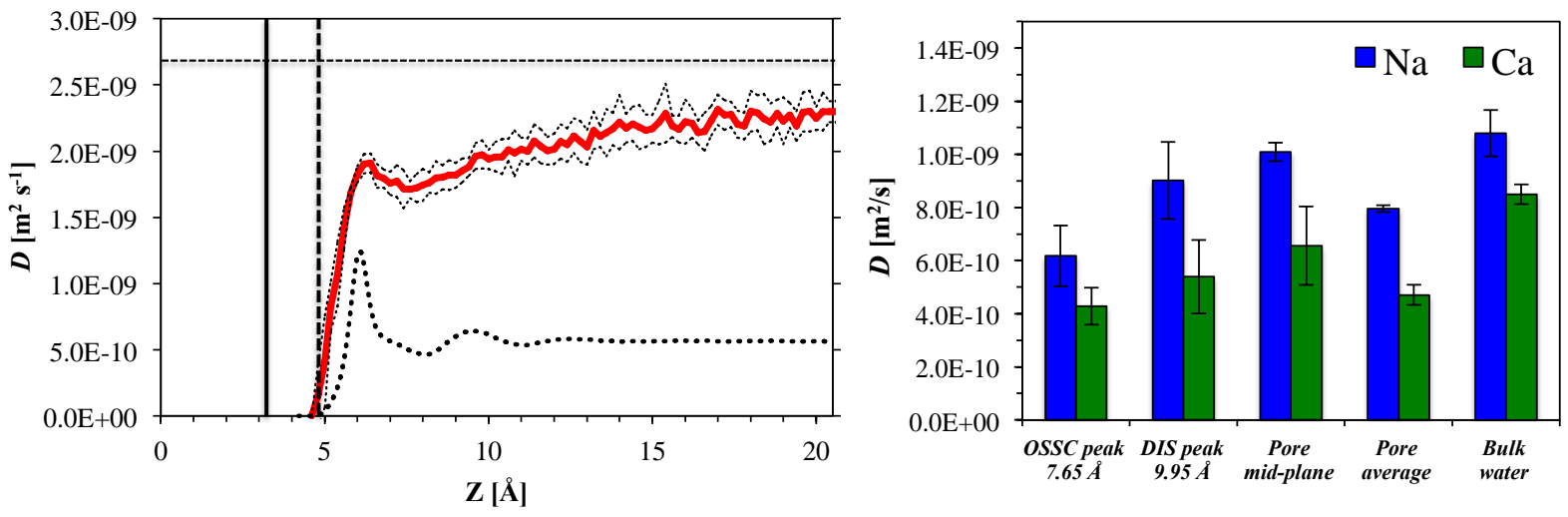

Fig. 9. Left: Molecular dynamics simulation prediction of the average diffusion coefficient of water $\mathrm{O}$ atoms in the $x y$-plane as a function of distance from the clay mineral surface, with confidence intervals shown as dashed lines. The self-diffusion coefficient of bulk liquid water is shown by the horizontal dashed line $\left(D=2.68 \cdot 10^{-9} \mathrm{~m}^{2} \cdot \mathrm{s}^{-1}\right.$ for the water model used in our MD simulations, Holmboe and Bourg (2014)); the density profile of water $\mathrm{O}$ atoms is shown by the thick dashed line, in arbitrary units. The vertical lines have the same meaning as in Fig. 7. Right: Average diffusion coefficients for $\mathrm{Na}$ and $\mathrm{Ca}$ near the density peaks at $z=7.65 \AA$ (OSSC) and $9.95 \AA$ (DIS) and near the pore mid-plane. Average diffusion coefficients in the entire pore and in bulk liquid water are shown for comparison. Note the halved scale compared to the left figure.

\section{Modeling and discussion}

The pore scale diffusion models compiled in Fig. 1 were tested for their ability to reproduce our macroscopic scale experimental results while also being in agreement with our MD simulation results. In the following, we present a comparison of the pore scale models with macroscopic and molecular scale anion exclusion results, as well as with $\mathrm{HTO}, \mathrm{Ca}$, and $\mathrm{Br}$ diffusion results. Our analysis allows us to draw conclusions regarding the accuracy of single and dual porosity conceptual models of diffusion in compacted smectite.

\subsection{Comparison of pore scale models with macroscopic and molecular scale anion exclusion results}

The LRC, BK, GRR and TY models (Fig. 1) can be qualified as single porosity EDL diffusion models insofar as the presence of bulk-liquid-like (i.e., non-EDL) water is not explicitly considered in these models. Our MD simulation results show that the Poisson-Boltzmann model 
1 (used in the GRR and TY models) and the mean potential model (used in the LCR and BK 2 models) can accurately predict mean anion concentrations in individual nanopores. In short, the 3 pore-scale treatments of anion exclusion in the LRC, BK, GRR, and TY models are qualitatively 4 consistent with MD simulation results, except for the fact that these models do not account for the 5 distance of closest approach of ions to the clay mineral-water interface.

6 In comparison, the AW model differs from the other pore-scale models in Fig. 1 insofar as it 7 allows for the existence of bulk-liquid-like water in the pore space of compacted clay. In the AW 8 model, the pore space of compacted clay is divided into bulk liquid water (occupying a fraction $f$ 9 of the pore space) and DIS water (or, equivalently, EDL water, the Stern layer being modeled as 10 a region of zero thickness). A mean electrostatic model is applied to the DIS water (Appelo et al., 11 2010), as described in further detail below. Using $\mathrm{Br}$ as an example, if DIS water has the same 12 density as bulk liquid water, and if $C_{i, \mathrm{DIS}}$ is the average concentration of species $i$ in the DIS, then 13 it follows that:

$$
\theta_{\mathrm{e}, \mathrm{Br}} \times C_{\mathrm{Br}, \text { bulk }}=f \theta_{\mathrm{HTO}} \times C_{\mathrm{Br}, \text { bulk }}+(1-f) \theta_{\mathrm{HTO}} C_{\mathrm{Br}, \mathrm{DIS}}
$$

14 In short, the AW model uses $f$ as a fitting parameter that can be constrained by macroscopic 15 anion-exclusion measurements. By comparison, the LRC and BK models make the assumption 16 that the EDL occupies the entire pore space $(f=0)$, while the GRR and TY models use the 17 Poisson-Boltzmann equation to evaluate the thickness of the EDL under the assumption that pore 18 width is uniform.

19 In the AW model, a mean electrostatic model is used to describe the equilibrium between bulk

20 liquid water and the diffuse ion swarm:

$$
C_{\mathrm{Br}, \mathrm{DIS}}=C_{\mathrm{Br}, \text { bulk }} \exp \left(\frac{F \psi_{\mathrm{DIS}}}{R T}\right)
$$

21 where $\psi_{\text {DIS }}$ is the mean electrostatic potential in the diffuse layer. Hence, it follows that:

$$
\frac{F \psi_{\mathrm{DIS}}}{R T}=\ln \left(\frac{\frac{\theta_{\mathrm{e}, \mathrm{Br}}}{\theta}-f}{1-f}\right)
$$

22 If we define $\sigma_{\mathrm{D}}$ as the surface charge that is compensated by ions in the DIS, we can express the 23 charge balance in the diffuse layer as follows:

$$
(1-f) \theta \sum_{i} z_{i} C_{i, \mathrm{DIS}}=-1000 \frac{a_{\mathrm{s}} \rho_{\mathrm{b}} \sigma_{\mathrm{D}}}{F}
$$

24 For conditions where $\mathrm{Ca}$ is present at trace levels (as in the present study), we obtain:

$$
\sigma_{\mathrm{D}}=\frac{-2 F \theta C_{\mathrm{Na}, \mathrm{bulk}}(1-f)}{1000 \times a_{\mathrm{s}} \rho_{\mathrm{b}}} \sinh \left(-\ln \left(\frac{\frac{\theta_{\mathrm{e}, \mathrm{Br}}}{\theta}-f}{1-f}\right)\right)
$$


1 The ratio $\theta_{\mathrm{e}, \mathrm{Br}} / \theta$ equals 0.74 according to our macroscopic adsorption experiments (section 3.1.2). 2 All other parameters in eq 22 are known and it is, thus, possible to relate the surface charge 3 compensated in the diffuse layer $\left(\sigma_{\mathrm{D}}\right)$ and the mean potential $\left(\psi_{\mathrm{DIS}}\right)$ to the value of $f$ (Appelo et 4 al., 2010). Fig. 10 demonstrates that, under our experimental conditions, if the Stern layer 5 contributes negligibly to screening the surface charge (as assumed in the BK model), our 6 measured values of $\theta_{\mathrm{e}, \mathrm{Br}} / \theta$ imply that $\mathrm{Br}$ is almost entirely restricted to the bulk liquid water 7 fraction of the pore space $\left(f \approx \theta_{\mathrm{e}, \mathrm{Br}} / \theta=0.74\right)$. In contrast, if the entire pore space is occupied by 8 the DIS, more than $90 \%$ of the surface charge must be screened by the Stern layer $\left(\sigma_{D} \sim\right.$ $\left.90.06 \cdot \sigma_{0}\right)$.

10 These results indicate that the LRC and BK models (based on a mean electrostatic model with $11 f=0$ ) and, by extension, the GRR and TY models (based on the Poisson-Boltzmann equation, 12 which predicts similar anion-exclusion to the mean electrostatic model with $f=0$ ) can only be 13 consistent with our macroscopic experimental results if more than $90 \%$ of the charge density $\sigma_{0}$ 14 is screened by the Stern layer. This condition is inconsistent with our MD simulation results, 15 which indicate that concentration profiles of $\mathrm{Na}, \mathrm{Ca}, \mathrm{Br}$, and $\mathrm{Cl}$ are consistent with the Poisson16 Boltzmann equation with little or no Stern layer. In short, the LRC, BK, GRR, and TY models 17 cannot be consistent with both our macroscopic scale experimental results and our MD simulation results. Of the pore scale models compiled in Fig. 1, only the AW model has the ability to be consistent with both experimental (showing $\theta_{\mathrm{e}, \mathrm{Br}} / \theta=0.74$ ) and MD simulation results (showing that the Stern layer screens less than $90 \%$ of the surface charge).

The AW model, however, only achieves consistency with our results by assuming that $f \approx 0.72$ 0.73 . This $f$ value would imply that the mean thickness of the EDL (whose fractional porosity value corresponds to $(1-f) \theta$ ) on the clay mineral surfaces equals

$$
d_{\mathrm{D}}=\frac{(1-f) \theta}{a_{\mathrm{s}} \rho_{\mathrm{b}} \times 10^{6}}
$$

24 with a resulting value of $d_{\mathrm{D}} \sim 3.4 \AA$. This distance, which is approximately equal to the diameter 25 of one water molecule, is too small to be representative of an EDL thickness. This result suggests, firstly, that the value of $f$ in the AW model should be viewed as an overall value of the fraction of DIS water in the entire pore space (not as a value of the fraction of DIS water in each individual nanopore). Secondly, it indicates that the pore space of the compacted clay in our experiments consisted of a mixture of many small pores and a few large pores (with the large pores contributing significantly to the bulk liquid water volume fraction $f$ without contributing much to the average EDL thickness $d_{\mathrm{D}}$ ). 


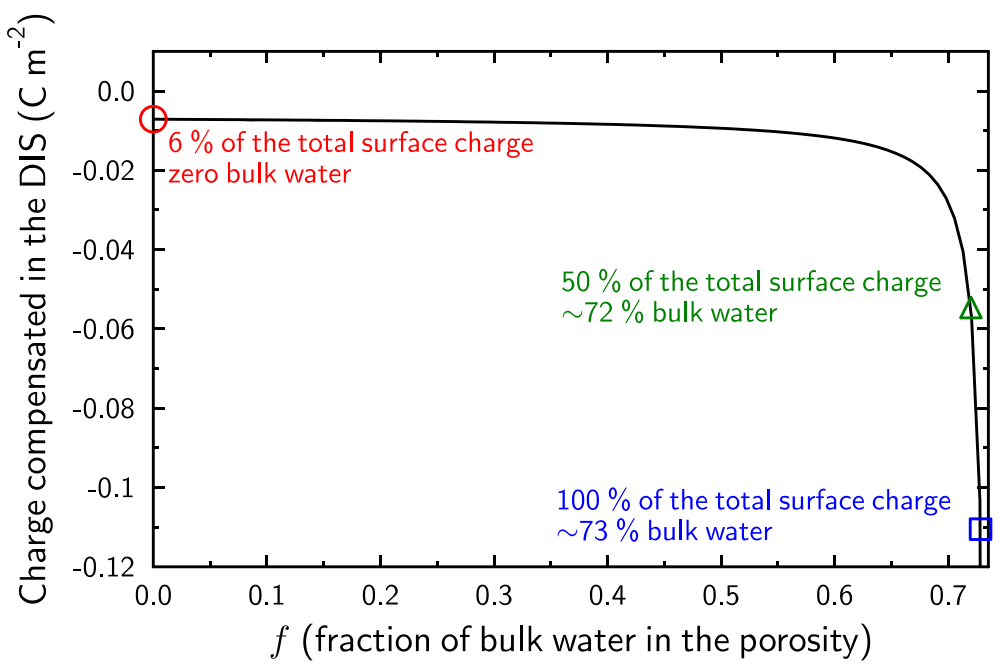

2 Fig. 10. Relationship between the surface charge compensated in the DIS (full line) and the

3 fraction of the pore space occupied by bulk liquid water $(f)$ according to eq 22 .

4 4.2. Comparison of pore scale models with macroscopic scale diffusion results

5 To further test the models in Fig. 1 against our macroscopic scale diffusion results, we 6 implemented the BK, LRC, and AW models in PHREEQC according to the methods described in 7 Appelo and Wersin (2007) and Appelo et al. (2010). Since PHREEQC requires the presence of 8 bulk liquid water in the porous medium, the BK and LRC models were implemented by defining 9 a very small volume of bulk water $(0.5 \%$ of the total water volume) that does not contribute 10 significantly to the mass balance or diffusive fluxes. The GRR and TY models were not 11 implemented, because PHREEQC does not allow for a solution to the full Poisson-Boltzmann 12 equation.

13 The BK model assumes that surface charge is completely balanced by DIS ions, while in the LRC 14 model a portion of the charge is screened by cations in the Stern layer. Stern layer adsorption of $15 \mathrm{Na}$ and $\mathrm{Ca}$ was taken into account by using the following reactions in the framework of the well16 known double layer model (DLM) (Dzombak and Morel, 1990; Parkhurst and Appelo, 1999):

$$
\begin{array}{ccc}
\text { Surf }^{-}+\mathrm{Na}^{+} \rightleftharpoons \text { SurfNa } & \log K_{N a} & 24 \\
2 \text { Surf }^{-}+\mathrm{Ca}^{2+} \rightleftharpoons \mathrm{Surf}_{2} \mathrm{Ca} & \log K_{C a} & 25
\end{array}
$$

17 The $\log K_{C a}$ value is constrained by the relative affinities of $\mathrm{Ca}^{2+}$ and $\mathrm{Na}^{+}$for the surface $\left[\log K_{\mathrm{Ca}}\right.$ $18-2 \log K_{\mathrm{Na}} \sim 0$ to 1 (Appelo et al., 2010)]. The $\log K_{\mathrm{Na}}$ value was adjusted to control the extent of 19 surface charge compensation by the Stern layer: a value of -99 results in no surface complexation 20 (BK model) while a value of +1.8 results in a compensation of $90 \%$ of the surface charge by $\mathrm{Na}^{+}$ 21 in the Stern layer (LRC model). The original version of the AW model used $\log K_{\mathrm{Na}}=-0.7$, 22 which results in $74 \%$ of the surface charge being compensated by the diffuse layer in a 0.1 $23 \mathrm{~mol} \cdot \mathrm{m}^{-3} \mathrm{NaCl}$ background electrolyte (Appelo and Wersin, 2007; Appelo et al., 2010). Results 24 from our MD simulations indicate that a $\log K_{\mathrm{Na}}$ value of 0 may be more appropriate, which 
1 results in $\sim 50 \%$ of the surface charge being compensated in the diffuse layer (Fig. 7). We note in 2 passing that, according to Fig. 10 , at $\log K_{\mathrm{Na}}$ values smaller than $\sim 1$, differences in this parameter 3 have little influence on anion-accessible porosity (or, equivalently, on $f$ ), while having a large 4 influence on cation partitioning between bulk water, DIS water, and the Stern layer.

5 It is possible to adequately fit $\mathrm{Ca}^{2+}$ and $\mathrm{Br}^{-}$diffusion data with both the $\mathrm{BK}$ and LRC models 6 using the parameters given in Table 3 (Fig. 11). In the BK model, it is necessary to decrease the mobility of $\mathrm{Ca}^{2+}$ by a factor of about 2.5 relative to water. This fitting result is in qualitative (but not quantitative) agreement with our MD simulation results, which showed that $q_{\text {nano }}(\mathrm{Ca})<$ $q_{\text {nano }}(\mathrm{HTO})$ (Table 2). However, a BK model fit also requires an increase in the $1 / \mathrm{G}$ value for $\mathrm{Br}^{-}$ compared to HTO by a factor of 5.3. Such an adjustment is unsupported by our MD simulations, which showed that $q_{\text {nano }}(\mathrm{Br}) \cong q_{\text {nano }}(\mathrm{HTO})$. In addition, while the $\mathrm{Br}^{-}$flux at steady state can be adequately reproduced by the $\mathrm{BK}$ model, the predicted onset of Br concentration increase occurs too early compared to our experimental results (Fig. 11). Overall, our calculations suggest that the BK model tends to underestimate the $\mathrm{Br}^{-}$accessible porosity (Table 3), which requires a greater, fitted $\mathrm{Br}^{-}$mobility in order to match the steady state diffusive flux data.

The LRC model was more successful than the BK model insofar as the simulated and experimentally determined $\mathrm{Br}$ accessible porosity values were in good agreement (the $\log K_{\mathrm{Na}}$ value was adjusted to obtain this agreement). Furthermore, the relative $1 / G$ values of HTO and $\mathrm{Br}^{-}$were in good agreement with their respective $q_{\text {nano }}$ values obtained from MD simulations. However, the fitted $1 / G_{\mathrm{Ca}}$ value was three times larger than $1 / G_{\mathrm{HTO}}$, which disagrees with our MD simulation results. As in the case of the Fickian model for $\mathrm{Ca}^{2+}$ diffusion (Fig. 6), it is difficult to justify the physical meaning of the very large $1 / G$ value of $\mathrm{Ca}^{2+}$ (relative to $\mathrm{HTO}$ and $\mathrm{Br}$ ) unless it is assumed that this large $1 / G$ value compensates for the assumed immobility of $\mathrm{Ca}^{2+}$ surface complexes in the LRC model.
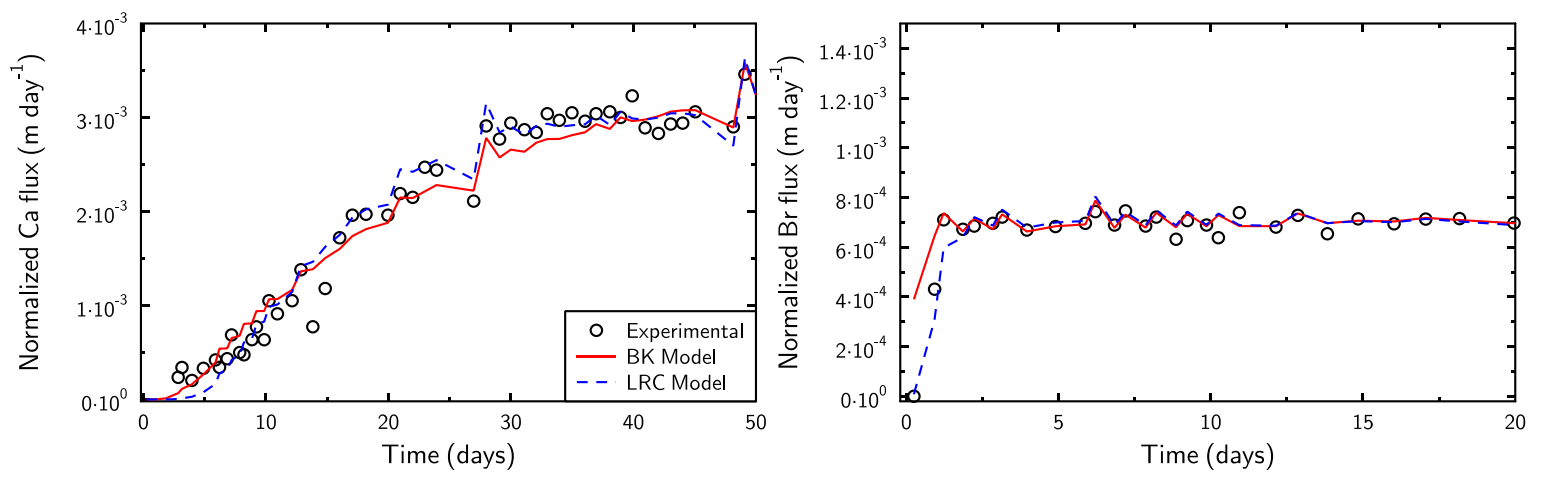

Fig. 11. Ca (left) and $\mathrm{Br}$ (right) mass flux densities as a function of time: experimental data (open circles), BK model (full red lines), and LRC model (dashed blue lines). See Fig. 1 for a description of models, and Table 3 for model parameters.

On the AW model, the diffusivity value in the DIS can be varied by defining a parameter $v_{\text {DIS }}$ that describes the ratio of the diffusion coefficients for a given species in bulk liquid water and in DIS 
1 water. For simplicity, we assume that $v_{\text {DIS }}$ has the same value for all species. Consequently, $G_{\mathrm{HTO}}$ 2 is constrained by our experimental results according to:

$$
\frac{(1-f)}{G_{\mathrm{HTO}}}+\frac{f}{v_{\mathrm{DIS}} G_{\mathrm{HTO}}}=0.047
$$

3 The value of $G_{\mathrm{Br}}$ is constrained in the same manner. If we neglect the contribution of the diffuse 4 layer to $\mathrm{Br}^{-}$diffusion, then

$$
\frac{(1-f)}{G_{\mathrm{Br}}} \sim 0.040 \times 0.55
$$

5 Based on this description of diffusion in bulk liquid and DIS water, the AW model (Fig. 12) 6 yields a good fit to the experimental data using the set of parameters given in Table 3. 7 Furthermore, the AW model provides results that are consistent with the measured anion 8 accessible porosity while also satisfying most of the constraints given by molecular dynamics 9 simulations. For instance, the mobility of all species is lower in DIS water than in bulk water. 10 According to our AW model fit, the ratio of diffusion coefficients in DIS water vs. bulk liquid 11 water is $1 / v_{\text {DIS }}=0.45$. Hence, the average ratio of HTO diffusion coefficients in the clay pore 12 water (DIS and bulk liquid water) to the diffusion coefficient of HTO in bulk liquid water is 13 equal to $f+1 / v_{\text {DIS }} \cdot(1-f)=0.86$. This value is larger than the value predicted by our MD 14 simulations, $q_{\text {nano }}=0.77 \pm 0.01$ (Table 2). The AW model also predicts that the $1 / G$ value of $\mathrm{Ca}^{2+}$ 15 is half that of HTO and $\mathrm{Br}^{-}$, which is in qualitative (but not quantitative) agreement with the 16 somewhat lower value of $q_{\text {nano }}$ predicted for Ca relative to $\mathrm{Br}^{-}$and $\mathrm{HTO}$ in our MD simulations 17 (Table 2).
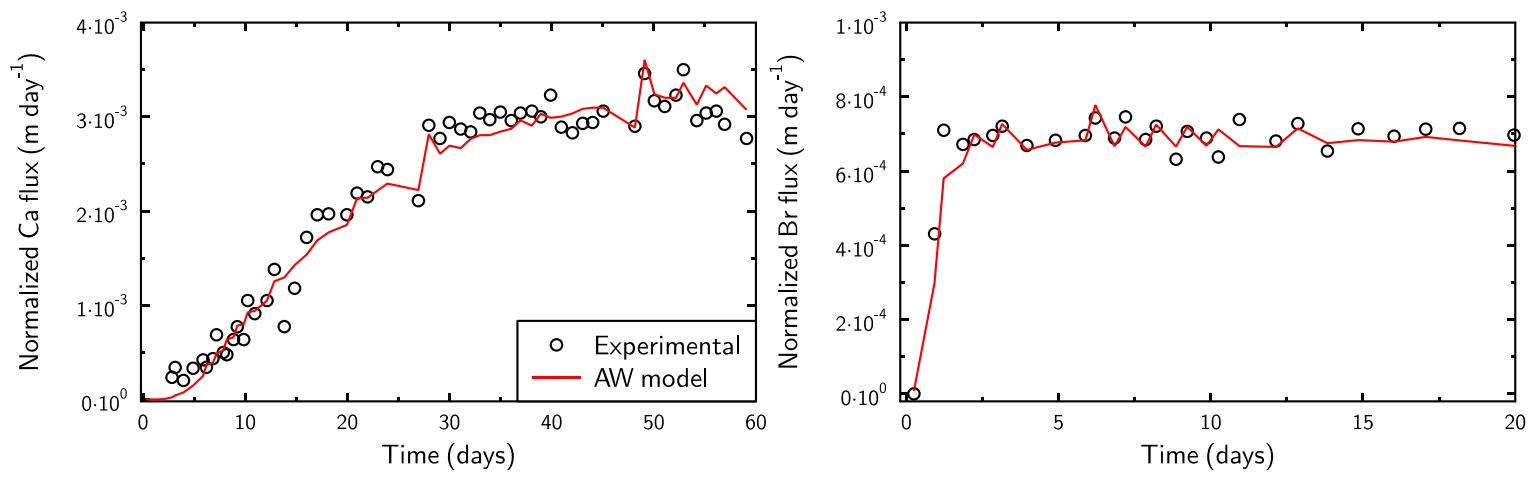

Fig. 12. Ca (left) and Br (right) mass flux densities as a function of time: experimental data (open 20 circles) and AW model (full red lines). See Fig. 1 for a description of the model and Table 3 for 21 model parameters.

23 Table 3. Diffusion and adsorption parameters for the BK, LRC, and AW models (see Fig. 1 for a 24 description of models). 


\begin{tabular}{|c|c|c|c|}
\hline & BK model & LRC model & AW model \\
\hline $\log K_{\mathrm{Na}}$ & $-99^{*}$ & 2.1 & 0 \\
\hline $\log K_{\mathrm{Ca}}$ & $-99^{*}$ & 4.7 & 0.5 \\
\hline $1 / G_{\mathrm{HTO}}$ & 0.047 & 0.047 & 0.056 \\
\hline $1 / G_{\mathrm{Br}}$ & 0.249 & 0.040 & 0.042 \\
\hline $1 / G_{\mathrm{Ca}}$ & 0.018 & 0.207 & 0.028 \\
\hline$f$ & - & - & 0.74 \\
\hline$v_{E D L}$ & - & - & 2.2 \\
\hline$\frac{\theta_{e, B r}}{\theta}$ & 0.1 & 0.74 & 0.74 \\
\hline
\end{tabular}

5. Summary

4 In this study, we tested a variety of pore-scale conceptual models for their ability to reproduce

5 macroscopic experimental diffusion data while being in agreement with molecular scale results

6 from MD simulations. Based on our findings, single-porosity pore scale models cannot be

7 simultaneously consistent with both macroscopic and molecular scale results. This discrepancy

8 suggests that single porosity models may oversimplify the microstructure of clayey media. Only a

9 model that conceptually divides the pore space of compacted clay into bulk liquid water and

10 diffuse ion swarm (DIS) water (AW model, Fig. 1) was able to simultaneously describe our

11 molecular and macroscopic scale results. Calculations carried out with the AW model suggest

12 that $70 \%$ of the pore space of our compacted clay is occupied by bulk liquid water. According to

13 our MD simulation results and Poisson-Boltzmann model calculations, such a large fraction of

14 bulk liquid water cannot exist in our experimental system if the pore size distribution is

15 unimodal. This finding is consistent with direct observations showing that compacted Na-

16 montmorillonite displays a significant microstructural complexity (Pusch, 2001; Melkior et al.,

17 2009) that can strongly impact anion accessible porosity (Tournassat and Appelo, 2011). Our

18 results, therefore, reveal that a very detailed experimental characterization of pore structure

19 (down to the resolution of the interlayer nanopores) as a function of dry density and electrolyte

20 concentration may be necessary to further constrain models of diffusion in clayey media. As a

21 first step, the existence of relatively large pores in compacted, water-saturated $\mathrm{Na}-$

22 montmorillonite at our experimental conditions (on the order of tens of nanometers and

23 accounting for $\sim 70 \%$ of the pore space, despite the significant swelling pressure of the material)

24 should be evaluated.

25 An alternative explanation for the failure of single porosity models to capture both macroscale

26 and pore scale behaviors could be that these models do not accurately describe adsorption and

27 diffusion at the pore scale. This hypothesis, however, is inconsistent with our findings. The

28 descriptions of adsorption and diffusion used in existing single porosity pore scale models largely 
1 agree with our MD simulation results. In particular, our atomistic simulations show that cation 2 adsorption and anion exclusion in individual nanopores are consistent with the Poisson3 Boltzmann equation used in the GRR and TY models (but with a distance of closest approach of 4 ions to the clay mineral surface, a feature absent from existing pore scale diffusion models). Our 5 MD simulation results on the adsorption of $\mathrm{Na}, \mathrm{Cl}$, and $\mathrm{Br}$ (but not $\mathrm{Ca}$ ) also are consistent with 6 the "mean electrostatic" approximation applied in the AW, LRC, and BK models. Our pore scale 7 simulations further indicate that a Stern layer is not necessary to describe the adsorption of $\mathrm{Na}^{+}$, $8 \mathrm{Ca}^{2+}, \mathrm{Cl}^{-}$, and $\mathrm{Br}^{-}$in Na-montmorillonite (MD simulation results are adequately described by a 9 Poisson-Boltzmann model calculation without a Stern layer). However, if $\mathrm{Na}^{+}$and $\mathrm{Ca}^{2+}$ outer10 sphere surface complexes (OSSC) are conceptually viewed as forming a Stern layer, then this 11 layer screens about $40 \%$ to $50 \%$ of the surface charge.

12 With regard to cation diffusion, our MD simulations clearly show that $\mathrm{Na}^{+}$and $\mathrm{Ca}^{2+}$ ions 13 adsorbed as OSSC retain a significant mobility. Therefore, a possible future improvement to the 14 conceptual diffusion models discussed here is the introduction of Stern layer diffusion (in 15 addition to diffusion in bulk liquid water and in DIS water). This approach, however, creates the 16 challenge of finding a unique distribution of properties for the three domains (bulk liquid water, 17 DIS water, and Stern layer) that can reproduce macroscopic diffusion data for cations, anions, 18 and neutral species while remaining in agreement with molecular scale information. In this study, 19 we did not attempt to develop such a model, because its parameterization would be under20 constrained by currently available data.

21 Finally, our results demonstrate that reactive transport modeling can improve the accuracy with 22 which diffusion and transport parameters are derived from diffusion experiments, by taking into 23 account the full geometry of the system (clay, filters, dead-volumes) as well as the specific nature of the sampling procedure. In the present study, reactive transport modeling results demonstrated that fluctuations in measured solute mass fluxes were primarily due to the timing of sampling events and not to other factors such as analytical uncertainties. 


\section{Acknowledgements}

2 This research was supported by the U.S. Department of Energy under Contract DE-AC023 05CH11231 under the auspices of the Used Fuel Disposition program (Office of Nuclear Energy)

4 and the Geosciences program (Office of Science, Office of Basic Energy Sciences) as well as by 5 the French Geologic Survey (BRGM) through the Institut Carnot BRGM. It used resources of the

6 National Energy Research Scientific Computing Center (NERSC), which is supported by the

7 Office of Science of the U.S. Department of Energy under Contract DE-AC02-05CH11231.

8 Financial support to M.H. by the Carl Tryggers Foundation, the Gålö foundation, and the 9 foundation BLANCEFLOR is gratefully acknowledged. The authors would like to thank Prof.

10 Jonsson and co-workers at the Applied Physical Chemistry, KTH, Sweden, for providing the 11 diffusion cells used in this study. 


\section{$1 \quad$ Notation}

$\begin{array}{rl}2 & A \\ 3 & a_{\mathrm{s}} \\ 4 & C_{\mathrm{b}} \\ 5 & C_{i, \text { bulk }} \\ 6 & C_{i, E D L} \\ 7 & C_{i, f r e e} \\ 8 & C_{i, \text { midplane }} \\ 9 & C_{i, p o r e} \\ 10 & C_{\text {low }} \\ 11 & C_{\text {high }} \\ 12 & d_{D} \\ 13 & d_{\text {pore }}^{\text {hom }} \\ 14 & D_{0} \\ 15 & D_{\mathrm{a}} \\ 16 & D_{\mathrm{e}} \\ 17 & D_{p} \\ 18 & D_{\text {pore }} \\ 19 & D_{\mathrm{s}} \\ 20 & f \\ 21 & F \\ 22 & G \\ 23 & G_{f} \\ 24 & h_{\text {pore }} \\ 25 & J \\ 26 & J_{N} \\ 27 & K_{\text {Ca }} \\ 28 & K_{\mathrm{D}} \\ 29 & K_{\mathrm{Na}} \\ 30 & \left\langle l^{2}\right\rangle \\ 31 & m_{i} \\ 32 & M \\ 33 & q_{\text {nano }} \\ 34 & R \\ 35 & t \\ 36 & T \\ 37 & V_{\text {low }} \\ 38 & x \\ 39 & z_{i} \\ 40 & \alpha \\ 41 & \Delta t \\ 42 & \theta \\ 43 & \theta_{e} \\ 44 & \theta_{f} \\ & \\ \\ \\ \\ \end{array}$

cross-sectional area available for diffusion $\left(\mathrm{m}^{2}\right)$ specific surface area of the material $\left(\mathrm{m}^{2} \cdot \mathrm{g}^{-1}\right)$ species concentration in bulk pore water $\left(\mathrm{mol} \cdot \mathrm{dm}^{-3}\right)$ species concentration in bulk pore water $\left(\mathrm{mol} \cdot \mathrm{dm}^{-3}\right)$ species concentration in diffuse layer $\left(\mathrm{mol} \cdot \mathrm{dm}^{-3}\right)$ species concentration in 'free' water $\left(\mathrm{mol} \cdot \mathrm{dm}^{-3}\right)$ species concentration at the interlayer midplane $\left(\mathrm{mol} \cdot \mathrm{dm}^{-3}\right)$ average species concentration in the entire nanopore $\left(\mathrm{mol} \cdot \mathrm{dm}^{-3}\right)$ solute concentration in low-concentration reservoir at time $t\left(\mathrm{~mol} \cdot \mathrm{dm}^{-3}\right)$ solute concentration in high-concentration reservoir at time $t\left(\mathrm{~mol} \cdot \mathrm{dm}^{-3}\right)$ mean electric double layer thickness $(\AA)$ average pore thickness (nm) self-diffusion coefficient in bulk liquid water $\left(\mathrm{m}^{2} \cdot \mathrm{s}^{-1}\right)$ apparent diffusion coefficient $\left(\mathrm{m}^{2} \cdot \mathrm{s}^{-1}\right)$ effective diffusion coefficient $\left(\mathrm{m}^{2} \cdot \mathrm{s}^{-1}\right)$ pore diffusion coefficient in macroscopic models $\left(\mathrm{m}^{2} \cdot \mathrm{s}^{-1}\right)$ two-dimensional diffusion coefficient in MD simulations $\left(\mathrm{m}^{2} \cdot \mathrm{s}^{-1}\right)$ surface diffusion coefficient $\left(\mathrm{m}^{2} \cdot \mathrm{s}^{-1}\right)$ 'free' water fraction of porosity (-) Faraday's constant $\left(96490 \mathrm{C} \cdot \mathrm{mol}^{-1}\right)$ geometric factor (-) geometric factor for metal filters (-) average pore width (nm) solute mass density in $x$ direction (e.g., $\mathrm{mol} \cdot \mathrm{s}^{-1} \cdot \mathrm{m}^{-2}$ ) normalized diffusive flux $\left(\mathrm{m} \cdot \mathrm{day}^{-1}\right)$ calcium surface complexation constant adsorption coefficient $\left(\mathrm{cm}^{-3} \cdot \mathrm{g}_{\text {or dm}}{ }^{-3} \cdot \mathrm{kg}\right)$ sodium surface complexation constant $\left(\mathrm{cm}^{-3} \cdot \mathrm{g} \mathrm{or} \mathrm{dm}^{-3} \cdot \mathrm{kg}\right)$ mean-square displacement of species as a function of time adsorbed solute per mass of clay $\left(\mathrm{mol} \cdot \mathrm{kg}^{-1}\right)$ mass of clay per volume of pore water $\left(\mathrm{kg} \cdot \mathrm{dm}^{-1}\right)$ parameter accounting for slow diffusion in vicinity of clay mineral surfaces (-) molar gas constant $\left(8.314 \mathrm{~J} \cdot \mathrm{mol}^{-1} \cdot \mathrm{K}^{-1}\right)$

time (s or day) temperature $(\mathrm{K})$ volume of low-concentration reservoir at time $t\left(\mathrm{~cm}^{-3}\right)$ distance $(\mathrm{m})$ ionic charge (-) rock capacity factor $(-)$ time interval between low-conc. reservoir solution replacements (day) total porosity of clay (-) effective or anion-accessible porosity (-) porosity of metal filters (-) 
$1 \quad v_{\text {DIS }}$

$2 \rho_{\mathrm{b}}$

$3 \rho_{d r y}$

$4 \quad \rho_{g}$

$5 \quad \sigma_{0}$

$6 \sigma_{D}$

$7 \tau$

$8 \phi$

$9 \phi_{\mathrm{e}}$

$10 \psi$

$11 \psi_{D I S}$

$12 \psi_{\text {midplane }}$

13

14 ratio of diffusion coefficients in bulk liquid water and DIS water (-) dry bulk density $\left(\mathrm{g} \cdot \mathrm{cm}^{-3}\right)$

dry density $\left(\mathrm{g} \cdot \mathrm{cm}^{-3}\right)$

crystal or grain density $\left(\mathrm{g} \cdot \mathrm{cm}^{-3}\right)$

surface charge $\left(\mathrm{C} \cdot \mathrm{m}^{-2}\right)$

surface charge compensated in diffuse layer $\left(\mathrm{C} \cdot \mathrm{m}^{-2}\right)$

time (ps)

porosity (-)

effective porosity accounting for anion exclusion (-)

surface potential (V)

mean electrostatic potential in the diffuse layer (V)

electrostatic potential at the midplane of the nanopore $(\mathrm{V})$ 
Aaqvist, J., 1990. Ion-water interaction potentials derived from free energy perturbation simulations. J. Phys. Chem. 94, 8021-8024.

Altmann, S., 2008. Geo'chemical research: A key building block for nuclear waste disposal safety cases. J. Contam. Hydrol. 102, 174-179.

Altmann, S., Tournassat, C., Goutelard, F., Parneix, J.-C., Gimmi, T., Maes, N., 2012. Diffusiondriven transport in clayrock formations. Appl. Geochem. 27, 463-478.

Andra, 2005. Référentiel du comportement des radionucléides et des toxiques chimiques d'un stockage dans le Callovo-Oxfordien jusqu'à l'Homme. Dossier 2005 Argile. Agence Nationale pour la gestion des déchets radioactifs, Châtenay-Malabry, France.

Appelo, C.A.J., Van Loon, L.R., Wersin, P., 2010. Multicomponent diffusion of a suite of tracers ( $\mathrm{HTO}, \mathrm{Cl}, \mathrm{Br}, \mathrm{I}, \mathrm{Na}, \mathrm{Sr}, \mathrm{Cs}$ ) in a single sample of Opalinus Clay. Geochim. Cosmochim. Acta 74, 1201-1219.

Appelo, C.A.J., Wersin, P., 2007. Multicomponent diffusion modeling in clay systems with application to the diffusion of tritium, iodide, and sodium in Opalinus clay. Env. Sci. Tech. 41, 5002-5007.

Bear, J., 1972. Dynamics of fluids in porous media. Courier Dover Publications.

Berendsen, H.J.C., Grigera, J.R., Straatsma, T.P., 1987. The missing term in effective pair potentials. J. Phys. Chem. 91, 6269-6271.

Birgersson, M., Karnland, O., 2009. Ion equilibrium between montmorillonite interlayer space and an external solution-Consequences for diffusional transport. Geochim. Cosmochim. Acta 73, 1908-1923.

Bock, H., Dehandschutter, B., Martin, C.D., Mazurek, M., De Haller, A., Skoczylas, F., Davy, C., 2010. Self-sealing fractures in argillaceous formations in the context of geological disposal of radioactive was ( No. 6184). Nuclear energy agency, organisation for economic co-operation and development.

Bourg, I.C., Sposito, G., 2010. Connecting the Molecular Scale to the Continuum Scale for Diffusion Processes in Smectite-Rich Porous Media. Env. Sci. Tech. 44, 2085-2091.

Bourg, I.C., Sposito, G., 2011. Molecular dynamics simulations of the electrical double layer on smectite surfaces contacting concentrated mixed electrolyte $\left(\mathrm{NaCl}-\mathrm{CaCl}_{2}\right)$ solutions. $J$. Colloid Interface Sci. 360, 701-715.

Bourg, I.C., Sposito, G., Bourg, A.C.M., 2006. Tracer diffusion in compacted, water-saturated bentonite. Clays Clay Miner. 54, 363-374.

Bourg, I.C., Tournassat, C., 2015. Chapter 6 - Self-diffusion of water and ions in clay barriers. In: Tournassat, C., Steefel, C.I., Bourg, I.C., Bergaya, F. (Eds.), Natural and Engineered Clay Barriers, Developments in Clay Science. Elsevier, pp. 71-100.

Bradbury, M.H., Baeyens, B., 2011. Predictive sorption modelling of Ni(II), Co(II), Eu(IIII), Th(IV) and U(VI) on MX-80 bentonite and Opalinus Clay: A "bottom-up" approach. Appl. Clay Sci. 52, 27-33.

Chipera, S.J., Bish, D.L., 2001. Baseline studies of the clay minerals society source clays: powder X-ray diffraction analyses. Clays Clay Miner. 49, 398-409.

Churakov, S.V., Gimmi, T., 2011. Up-scaling of molecular diffusion coefficients in clays: A twostep approach. J. Phys. Chem. C. 115, 6703-6714.

Costanzo, P., Guggenheim, S., 2001. Baseline studies of the Clay Minerals Society source clays: preface. Clays Clay Miner. 49, 371-371. 
Cygan, R.T., Liang, J.-J., Kalinichev, A.G., 2004. Molecular models of hydroxide, oxyhydroxide, and clay phases and the development of a general force field. J. Phys. Chem. B 108, 1255-1266.

Davis, J.A., James, R.O., Leckie, J.O., 1978. Surface ionization and complexation at the oxide/water interface: I. Computation of electrical double layer properties in simple electrolytes. J. Colloid Interface Sci. 63, 480-499.

Delay, J., Vinsot, A., Krieguer, J.-M., Rebours, H., Armand, G., 2007. Making of the underground scientific experimental programme at the Meuse/Haute-Marne underground research laboratory, North Eastern France. Phys. Chem. Earth, Parts A/B/C 32, 2-18.

Duc, M., Thomas, F., Gaboriaud, F., 2006. Coupled chemical processes at clay/electrolyte interface: A batch titration study of Na-montmorillonites. J. Colloid Interface Sci. 300, 616-625.

Dykhuizen, R.C., Casey, W.H., 1989. An analysis of solute diffusion in rocks. Geochim. Cosmochim. Acta 53, 2797-2805.

Dzombak, D.A., Morel, F.M.M., 1990. Surface complexation modeling-Hydrous ferric oxide. New York.

Englert, M., Krall, L., Ewing, R.C., 2012. Is nuclear fission a sustainable source of energy? MRS bulletin 37, 417-424.

Ferrage, E., Lanson, B., Sakharov, B.A., Drits, V.A., 2005. Investigation of smectite hydration properties by modeling experimental X-ray diffraction patterns: Part I. Montmorillonite hydration properties. Am. Mineral. 90, 1358-1374.

Gajo, A., Loret, B., 2007. The mechanics of active clays circulated by salts, acids and bases. Journal of the Mechanics and Physics of Solids 55, 1762-1801.

Gimmi, T., Kosakowski, G., 2011. How mobile are sorbed cations in clays and clay rocks? Env. Sci. Tech. 45, 1443-1449.

Glaus, M.A., Aertsens, M., Maes, N., Van Laer, L., Van Loon, L.R., 2015. Treatment of boundary conditions in through-diffusion: A case study of ${ }^{85} \mathrm{Sr}^{2+}$ diffusion in compacted illite. J. Contam. Hydrol. 177, 239-248.

Glaus, M.A., Frick, S., Rosse, R., Van Loon, L.R., 2010. Comparative study of tracer diffusion of HTO, Na-22(+) and Cl-36(-) in compacted kaolinite, illite and montmorillonite. Geochim. Cosmochim. Acta 74, 1999-2010.

Gonçalvès, J., Rousseau-Gueutin, P., Revil, A., 2007. Introducing interacting diffuse layers in TLM calculations: A reappraisal of the influence of the pore size on the swelling pressure and the osmotic efficiency of compacted bentonites. Journal of Colloid and Interface Science 316, 92-99.

Gonzàlez Sànchez, F., Gimmi, T., Juranyi, F., Van Loon, L., Diamond, L.W., 2009. Linking the Diffusion of Water in Compacted Clays at Two Different Time Scales: Tracer ThroughDiffusion and Quasielastic Neutron Scattering. Env. Sci. Tech. 43, 3487-3493.

Guyonnet, D., Touze-Foltz, N., Norotte, V., Pothier, C., Didier, G., Gailhanou, H., Blanc, P., Warmont, F., 2009. Performance-based indicators for controlling geosynthetic clay liners in landfill applications. Geotext. Geomembranes 27, 321-331.

Hockney, R.W., Eastwood, J.W., 1988. Computer simulation using particles. Hilger (Bristol England and Philadelphia).

Holmboe, M., Bourg, I.C., 2014. Molecular dynamics simulations of water and sodium diffusion in smectite interlayer nanopores as a function of pore size and temperature. J. Phys. Chem. C. 118, 1001-1013. 
Holmboe, M., Karin Norrfors, K., Jonsson, M., Wold, S., 2011. Effect of textgreekg-radiation on radionuclide retention in compacted bentonite. Radiat. Phys. Chem. 80, 1371-1377.

Holmboe, M., Wold, S., Jonsson, M., 2010. Colloid diffusion in compacted bentonite: microstructural constraints. Clays Clay Miner. 58, 532-541.

Holmboe, M., Wold, S., Jonsson, M., 2012. Porosity investigation of compacted bentonite using XRD profile modeling. J. Contam. Hydrol. 128, 19-32.

Horseman, S.T., Volckaert, G., 1996. Disposal of radioactive wastes in argillaceous formations. Geological Society, London, Engineering Geology Special Publications 11, 179-191.

Isele-Holder, R.E., Mitchell, W., Ismail, A.E., 2012. Development and application of a particleparticle particle-mesh Ewald method for dispersion interactions. J. Chem. Phys. 137, 174107.

Jackson, M.L., 1975. Soil chemical analysis - advanced course 2nd edition. Published by the author, University of Wisconsin, Madison, Wisconsin.

Jakob, A., Pfingsten, W., Van Loon, L.R., 2009. Effects of sorption competition on caesium diffusion through compacted argillaceous rock. Geochim. Cosmochim. Acta 73, 24412456.

Jardat, M., Dufreche, J.F., Marry, V., Rotenberg, B., Turq, P., 2009. Salt exclusion in charged porous media: a coarse-graining strategy in the case of montmorillonite clays. Phys. Chem. Chem. Phys. 11, 2023-2033.

Jenny, H., Overstreet, R., 1939. Surface Migration of Ions and Contact Exchange. J. Phys. Chem. 43, 1185-1196.

Jo, H.Y., Benson, C.H., Edil, T.B., 2006. Rate-limited cation exchange in thin bentonitic barrier layers. Can. Geotech. J. 43, 370-391.

Joseph, C., Schmeide, K., Sachs, S., Brendler, V., Geipel, G., Bernhard, G., 2011. Sorption of uranium (VI) onto Opalinus Clay in the absence and presence of humic acid in Opalinus Clay pore water. Chem. Geol. 284, 240-250.

Jougnot, D., Revil, A., Leroy, P., 2009. Diffusion of ionic tracers in the Callovo-Oxfordian clayrock using the Donnan equilibrium model and the formation factor. Geochim. Cosmochim. Acta 73, 2712-2726.

Joung, I.S., Cheatham, T.E.I., 2009. Molecular dynamics simulations of the dynamic and energetic properties of alkali and halide ions using water-model-specific ion parameters. J. Phys. Chem. B 113, 13279-13290.

Keller, L.M., Holzer, L., Schuetz, P., Gasser, P., 2013. Pore space relevant for gas permeability in Opalinus clay: Statistical analysis of homogeneity, percolation, and representative volume element. J. Geophys. Res. 118, 2799-2812.

Kemper, W.D., Maasland, D.E.L., Porter, L.K., 1964. Mobility of water adjacent to mineral surfaces. Soil Sci. Soc. Am. J. 28, 164-167.

Kemper, W.D., Rollins, J.B., 1966. Osmotic efficiency coefficients across compacted clays. Soil Sci. Soc. Am. J. 30, 529-534.

Kerisit, S., Liu, C., 2010. Molecular simulation of the diffusion of uranyl carbonate species in aqueous solution. Geochim. Cosmochim. Acta 74, 4937-4952.

Laird, D.A., Shang, C., 1997. Relationship between cation exchange selectivity and crystalline swelling in expanding 2:1 phyllosilicates. Clays Clay Miner. 45, 681-689.

Leroy, P., Revil, A., Coelho, D., 2006. Diffusion of ionic species in bentonite. J. Colloid Interface Sci. 296, 248-255.

Li, Y.-H., Gregory, S., 1974. Diffusion of ions in sea water and in deep-sea sediments. Geochim. Cosmochim. Acta 38, 703-714. 
Loomer, D.B., Scott, L., Al, T.A., Mayer, K.U., Bea, S., 2013. Diffusion-reaction studies in low permeability shale using X-ray radiography with cesium. Appl. Geochem. 39, 49-58.

Marry, V., Rotenberg, B., Turq, P., 2008. Structure and dynamics of water at a clay surface from molecular dynamics simulation. Phys. Chem. Chem. Phys. 10, 4802-4813.

Marry, V., Turq, P., Cartailler, T., Levesque, D., 2002. Microscopic simulation for structure and dynamics of water and counterions in a monohydrated montmorillonite. J. Chem. Phys. 117, 3454-3463.

Mazurek, M., Alt-Epping, P., Bath, A., Gimmi, T., Niklaus Waber, H., Buschaert, S., Cannière, P.D., De Craen, M., Gautschi, A., Savoye, S., Vinsot, A., Wemaere, I., Wouters, L., 2011. Natural tracer profiles across argillaceous formations. Appl. Geochem. 26, 1035-1064.

Melkior, T., Gaucher, E.C., Brouard, C., Yahiaoui, S., Thoby, D., Clinard, C., Ferrage, E., Guyonnet, D., Tournassat, C., Coelho, D., 2009. $\mathrm{Na}^{+}$and HTO diffusion in compacted bentonite: Effect of surface chemistry and related texture. J. Hydrol. 370, 9-20.

Mermut, A.R., Cano, A.F., 2001. Baseline studies of the clay minerals society source clays: chemical analyses of major elements. Clays Clay Miner. 49, 381-386.

Molera, M., 2002. On the sorption and diffusion of radionuclides in Bentonite Clay. Ph. D. thesis, Royal Institute of Technolgy, Stockholm.

Molera, M., Eriksen, T., 2002. Diffusion of ${ }^{22} \mathrm{Na}^{+},{ }^{85} \mathrm{Sr}^{2+},{ }^{134} \mathrm{Cs}^{+}$and ${ }^{57} \mathrm{Co}^{2+}$ in bentonite clay compacted to different densities: experiments and modeling. Radiochim. Acta 90, 753760.

Molera, M., Eriksen, T., Jansson, M., 2003. Anion diffusion pathways in bentonite clay compacted to different dry densities. Appl. Clay Sci. 23, 69-76.

Montavon, G., Guo, Z., Tournassat, C., Grambow, B., Le Botlan, D., 2009. Porosities accessible to HTO and iodide on water-saturated compacted clay materials and relation with the forms of water: A low field proton NMR study. Geochim. Cosmochim. Acta 73, 72907302.

Muurinen, A., Karnland, O., Lehikoinen, J., 2004. Ion concentration caused by an external solution into the porewater of compacted bentonite. Phys. Chem. Earth, Parts A/B/C 29, 119-127.

Muurinen, A., Karnland, O., Lehikoinen, J., 2007. Effect of homogenization on the microstructure and exclusion of chloride in compacted bentonite. Phys. Chem. Earth, Parts A/B/C 32, 485-490.

Nadeau, P.H., 1985. The physical dimensions of fundamental clay particles. Clay Miner. 20, 499.

Neuzil, C.E., 1986. Groundwater flow in low-permeability environments. Water Resour. Res. 22, $1163-1195$.

Neuzil, C.E., 1994. How permeable are clays and shales? Water Resour. Res. 30, 145-150.

Neuzil, C.E., 2013. Can shale safely host US nuclear waste? EOS, Trans. Am. Geophys. Union 94, 261-262.

Neuzil, C.E., Provost, A.M., 2009. Recent experimental data may point to a greater role for osmotic pressures in the subsurface. Water Resour. Res. 45.

Nye, P.H., 1980. Diffusion of ions and uncharged solutes in soils and soil clays. Adv. Agron. 31, 225-272.

Oscarson, D.W., Dixon, D.A., Hume, H.B., 1996. Mass transport through defected bentonite plugs. Appl. Clay Sci. 11, 127-142.

Pacala, S., Socolow, R., 2004. Stabilization wedges: solving the climate problem for the next 50 years with current technologies. Science 305, 968-972. 
Parkhurst, D.L., Appelo, C.A.J., 1999. User's guide to PHREEQC (Version 2) - A computer program for speciation, batch-reaction, one-dimensional transport, and inverse geochemical calculations ( No. Denver, CO. U.S. Geological Survey. Water resources investigations report 99-4259. 312 p.).

Parkhurst, D.L., Appelo, C.A.J., 2013. Description of Input and Examples for PHREEQC Version 3-a Computer Program for Speciation, Batch-reaction, One-dimensional Transport, and Inverse Geochemical Calculations.

Plimpton, S., 1995. Fast parallel algorithms for short-range molecular dynamics. J. Comput. Phys. 117, 1-19.

Pusch, R., 2001. The microstructure of MX-80 clay with respect to its bulk physical properties under different environmental conditions. SKB, TR-01-08.

Ryckaert, J.-P., Ciccotti, G., Berendsen, H.J.C., 1977. Numerical integration of the cartesian equations of motion of a system with constraints: molecular dynamics of $n$-alkanes. $J$. Comput. Phys. 23, 327-341.

Sato, H., 2008. Thermodynamic model on swelling of bentonite buffer and backfill materials. Phys. Chem. Earth, Parts A/B/C 33, S538-S543.

Savoye, S., Goutelard, F., Beaucaire, C., Charles, Y., Fayette, A., Herbette, M., Larabi, Y., Coelho, D., 2011. Effect of temperature on the containment properties of argillaceous rocks: The case study of Callovo-Oxfordian claystones. J. Contam. Hydrol. 125, 102112.

Savoye, S., Page, J., Puente, C., Imbert, C., Coelho, D., 2010. New experimental approach for studying diffusion through an intact and unsaturated medium: a case study with CallovoOxfordian argillite. Env. Sci. Tech. 44, 3698-3704.

Shackelford, C.D., Moore, S.M., 2013. Fickian diffusion of radionuclides for engineered containment barriers: Diffusion coefficients, porosities, and complicating issues. Eng. Geol. 152, 133-147.

Simpson, J.H., Carr, H.Y., 1958. Diffusion and nuclear spin relaxation in water. Phys. Rev. 111, 1201.

SKB, 2011. Long-term safety for the final repository for spent nuclear fuel at Forsmark. Main report of the SR-Site project. Volume I. SKB - TR-11-01.

Sposito, G., 1992. The diffuse-ion swarm near smectite particles suspended in 1:1 electrolyte solutions: modified Gouy-Chapman theory and quasicrystal formation. In: Güven, N., Pollastro, R.M. (Eds.), Clay water interface and its rheological implications. Clay minerals society, pp. 127-156.

Sposito, G., 2004. The surface chemistry of natural particles. Oxford University Press, New York.

Sposito, G., Skipper, N.T., Sutton, R., Park, S., Soper, A.K., 1999. Surface geochemistry of the clay minerals. Proc. Natl. Acad. Sci. U. S. A. 96, 3358-3364.

Swift, A.M., Anovitz, L.M., Sheets, J.M., Cole, D.R., Welch, S.A., Rother, G., 2014. Relationship between mineralogy and porosity in seals relevant to geologic $\mathrm{CO} 2$ sequestration. Environ. Geosci. 21, 39-57.

Tachi, Y., Yotsuji, K., 2014. Diffusion and sorption of $\mathrm{Cs}^{+}, \mathrm{Na}^{+}, \mathrm{I}^{-}$and HTO in compacted sodium montmorillonite as a function of porewater salinity: Integrated sorption and diffusion model. Geochim. Cosmochim. Acta 132, 75-93.

Tachi, Y., Yotsuji, K., Suyama, T., Ochs, M., 2014. Integrated sorption and diffusion model for bentonite. Part 2: porewater chemistry, sorption and diffusion modeling in compacted systems. J. Nucl. Sci. Technol. 51, 1-14. 
Tertre, E., Pret, D., Ferrage, E., 2011. Influence of the ionic strength and solid/solution ratio on $\mathrm{Ca}$ (II)-for-Na+ exchange on montmorillonite. Part 1: Chemical measurements, thermodynamic modeling and potential implications for trace elements geochemistry. $J$. Colloid Interface Sci. 353, 248-256.

Tournassat, C., Appelo, C.A.J., 2011. Modelling approaches for anion-exclusion in compacted Na-bentonite. Geochim. Cosmochim. Acta 75, 3698-3710.

Tournassat, C., Chapron, Y., Leroy, P., Boulahya, F., 2009. Comparison of molecular dynamics simulations with Triple Layer and modified Gouy-Chapman models in a $0.1 \mathrm{M} \mathrm{NaCl}$ montmorillonite system. J. Colloid Interface Sci. 339, 533-541.

Tournassat, C., Neaman, A., Villiéras, F., Bosbach, D., Charlet, L., 2003. Nanomorphology of montmorillonite particles: Estimation of the clay edge sorption site density by lowpressure gas adsorption and AFM observations. Am. Mineral. 88, 1989-1995.

Van Loon, L.R., Glaus, M.A., Müller, W., 2007. Anion exclusion effects in compacted bentonites: Towards a better understanding of anion diffusion. Appl. Geochem. 22, 25362552.

Van Loon, L.R., Soler, J.M., Bradbury, M.H., 2003a. Diffusion of $\mathrm{HTO},{ }^{36} \mathrm{Cl}^{-}$and ${ }^{125} \mathrm{I}^{-}$in Opalinus Clay samples from Mont Terri: Effect of confining pressure. J. Contam. Hydrol. $61,73-83$.

Van Loon, L.R., Soler, J.M., Jakob, A., Bradbury, M.H., 2003b. Effect of confining pressure on the diffusion of HTO, 36Cl- and 125I- in a layered argillaceous rock (Opalinus Clay): diffusion perpendicular to the fabric. Appl. Geochem. 18, 1653-1662.

Van Schaik, J., Kemper, W., 1966. Chloride diffusion in clay-water systems. Soil Sci. Soc. Am. J. $30,22-25$.

Van Schaik, J., Kemper, W., Olsen, S., 1966. Contribution of adsorbed cations to diffusion in clay-water systems. Soil Sci. Soc. Am. J. 30, 17-22.

Wang, Q., Tang, A.M., Cui, Y.-J., Barnichon, J.-D., Ye, W.-M., 2013. Investigation of the hydromechanical behaviour of compacted bentonite/sand mixture based on the BExM model. Comput. Geotech. 54, 46-52.

Wang, X., Liu, X., 2004. Effect of $\mathrm{pH}$ and concentration on the diffusion of radiostrontium in compacted bentonite - a capillary experimental study. Appl. Radiat. Isot. 61, 1413-1418.

Wersin, P., Curti, E., Appelo, C.A.J., 2004. Modelling bentonite-water interactions at high solid/liquid ratios: swelling and diffuse double layer effects. Appl. Clay Sci. 26, 249-257.

Yokoyama, S., Kuroda, M., Sato, T., 2005. Atomic force microscopy study of montmorillonite dissolution under highly alkaline conditions. Clays Clay Miner. 53, 147-154.

Zachara, J.M., Smith, S.C., 1994. Edge complexation reactions of cadmium on specimen and soil-derived smectite. Soil Sci. Soc. Am. J. 58, 762-769. 